\title{
35. AN EXPERIMENT OF IN-SITU STRESS ESTIMATION ON BASALTIC ROCK CORE SAMPLES FROM HOLE 758A, NINETYEAST RIDGE, INDIAN OCEAN ${ }^{1}$
}

\author{
Kensaku Tamaki, ${ }^{2}$ Kiyohiko Yamamoto, ${ }^{3}$ Toshio Furuta, ${ }^{4}$ and Hidekazu Yamamoto ${ }^{3}$
}

\begin{abstract}
We carried out an experiment to estimate in-situ stresses at ODP Hole 758A (water depth: $2924 \mathrm{~m}$ ) from the basaltic core samples by a new method, deformation rate analysis (DRA). Stress previously applied to a rock specimen is identified in inelastic strain behavior of the specimen under uniaxial compression by this method. Although the identification of the previous stresses by the DRA was difficult because of small fracture strengths of the samples, we could find the previous stresses which are considered to correspond to the in-situ stresses. The vertical, the maximum, and the minimum horizontal in-situ stresses estimated are $(37.8,36.6$, $26.8 \mathrm{MPa}),(40.6,40.1,28.6 \mathrm{MPa})$, and $(41.2,40.6,30.4 \mathrm{MPa})$, respectively, for Cores 121-758A-55R (502 mbsf), -64R (583 mbsf), and $-69 \mathrm{R}(639 \mathrm{mbsf})$. The estimated in-situ vertical stress is equal to the calculated overburden pressure with an error less than $3 \%$ at each depth. The maximum horizontal stresses are nearly equal to the vertical ones. This suggests that the site is in the stress field of the normal fault regime at the depths. We measured the stable magnetization directions of our samples in order to estimate their azimuthal orientations. The site was affected by a maximum of $10^{\circ}$ of counterclockwise rotation since the basaltic rocks were magnetized. Referring to the paleomagnetic orientations, the estimated in-situ directions of the maximum horizontal stress range from $\mathrm{N} 16^{\circ} \mathrm{W}$ to $\mathrm{N} 63^{\circ} \mathrm{W}$. The directions are not greatly different from the regional stress field at the site. The DRA needs more experiments in deep-sea cores, in conjunction with another in-situ stress measurement such as a borehole televiewer and the packer/hydrofracturing method, to become a useful method.
\end{abstract}

\section{INTRODUCTION}

Knowledge of the stress state in the oceanic crust is crucial in addressing plate motions and their driving force. Many methods for determining the state of stress in the crust have been developed in order to understand actual stress conditions of the crust and of lithospheric plates; these include methods based on natural fracture distribution (Hickman et al., 1985), borehole breakouts (Newmark et al., 1983; Zoback et al., 1985), borehole guided waveforms (Barton and Zoback, 1988), and the packer/hydrofracturing method (McGarr and Gay, 1978), among others. Newmark et al. (1983) observed breakouts in Deep Sea Drilling Project (DSDP) Hole 504B with a borehole televiewer (BHTV) to determine the direction of the horizontal principal stresses. They investigated the relationship between the direction of the principal axes and the location of the Costa Rica Rift and the Peru-Chile Trench, from which they showed that the directions of the principal stresses can be interpreted in terms of the two postulated driving mechanisms for the motion of lithosphere: ridge push and slab pull. The method based on borehole breakouts originally lacked information for addressing the magnitude of stress; however, it is now sufficiently sophisticated to detect the magnitude of stress through the detailed analyses of breakout shape (Zheng et al., 1989). Another commonly used borehole method is the packer/hydrofracturing experiment, which is used to measure both magnitude and direction of the stress field. The packer/hydrofracturing method, however, is rarely successful because the method requires clean and stable hole conditions and also needs a long operation time.

The other approach to estimate in-situ stress state is to estimate it from rock cores of boreholes. Many efforts have been made and

\footnotetext{
'Weissel, J., Peirce, J., Taylor, E., Alt, J., et al., 1991. Proc. ODP, Sci. Results, 121: College Station, TX (Ocean Drilling Program).

${ }^{2}$ Ocean Research Institute, University of Tokyo, Minamidai, Nakano, Tokyo 164, Japan.

${ }^{3}$ Faculty of Science, Tohoku University, Sendai 980, Japan.

${ }^{4}$ Oki Electric Industry, Co. Ltd., Numazu 410, Japan.
}

continue to be made to develop the methods and the techniques through this approach. Kanagawa et al. (1977) measured the activity of acoustic emissions (AE) in rock specimens during loading of uniaxial compression to demonstrate that the applied stress where the activity begins to increase is nearly equal in value to the in-situ stresses to which the specimen has been subjected. The method is called the AE method. Yoshikawa and Mogi (1981) also proposed an AE method. Simmons et al. (1974) and Siegfried and Simmons (1978) presented a method called differential strain analysis (DSA) for the estimation of crack orientation and aspect ratio distribution of cracks in rocks.

A method called differential strain curve analysis (DSCA) has been developed on the basis of the DSA to determine the principal axes as well as the ratios of the principal values of in-situ stress (Strickland and Ren, 1980; Montgomery and Ren, 1981; and Ren and Roegiers, 1983). Their method assumes that a core sample isolated from its downhole confined condition will expand proportionally to the preexisting in-situ stress field. A method called deformation rate analysis (DRA) was proposed by Yamamoto et al. $(1983,1990)$ for the discrimination of the stress previously applied to a specimen using behavior of inelastic strain of the specimen under uniaxial compression. This method is similar to the $\mathrm{AE}$ method from the viewpoint that both of them utilize inelastic properties of rocks under compression. Yamamoto et al. $(1989,1990)$ applied this method to borehole samples to demonstrate that the measured magnitude of the previously applied stress can be regarded as the in-situ stress, and that the method is applicable to the estimation of in-situ stresses for many types of rocks.

In the present experiment, we employ the DRA to estimate in-situ stresses. Although the principles have not been established as yet, the concept and the previous results of the DRA will be briefly introduced in the next section. This is the first time that this method is applied to marine core samples. Because we are trying to contribute to the earlier efforts to determine the in situ stress in the oceanic crust, we will present supplementary information on the stress state of the oceanic crust other than that obtained by in-situ stress measurements. One of advantages of our 
approach is the likelihood of determining information about the magnitude and orientation of pseudo-in-situ stresses when hardrock core samples are available. The magnitude of vertical stress is especially difficult to obtain by the other methods.

Site 758 is located on the summit of the northern end of Ninetyeast Ridge at the position of $5^{\circ} 23.049^{\prime} \mathrm{N}$ and $90^{\circ} 21.673^{\prime} \mathrm{E}$ (Fig. 1). Hole 758A reached Campanian sediments and penetrated $178 \mathrm{~m}$ of basaltic rocks (Shipboard Scientific Party, 1989). The site is, to the north, close to the collision zone between India and Eurasia and also close to the Sunda Trench to the northeast. We use the declination of natural remanent magnetization (NRM) as a reference of the orientation of the estimated in-situ horizontal stresses. The NRM north, however, may be shifted $10^{\circ}$ counterclockwise from the in-situ north of the samples because the Indo-Australian plate on which Site 758 is located was rotated $10^{\circ}$ counterclockwise since the Campanian (Morgan, 1981).

\section{DEFORMATION RATE ANALYSIS AND IN-SITU STRESS MEMORY}

\section{Deformation Rate Analysis}

The AE in a specimen becomes active at the applied stresses larger than the peak stress previously applied to the sample under a uniaxial compression test. This property is known as the Kaiser effect of AE. We can infer from the Kaiser effect that the inelastic strain begins to increase at higher rates as increases in applied stress, at a constant stress rate exceed the previous peak stress. Further, we can expect from the shear microfracturing models, which were originally proposed by Brace et al. (1966) and developed by Stevens and Holcomb (1980) and Kuwahara et al. (1990), that the inelastic strain increases linearly to applied stress while the applied stress is less than the previous applied peak stress. Yamamoto et al. (1990) experimentally confirmed the strain behavior under uniaxial compression tests. The behavior implies that the previous peak stress can be observed as a change in the gradient of the stress-strain relation. The gradient changes have scarcely been discriminated in the stress-strain relations obtained by conventional techniques in the case of small previous stresses, because the change is buried in the larger nonlinearity of stressstrain relations due to other sources, for example, crack or pore closure (Walsh, 1965; Simmons et al., 1974; Siegfried and Simmons, 1978). Yamamoto et al. (1990) performed cyclic uniaxial loading tests and took differences of strain during loading between two cycles as a function of the applied stress as follows,

$$
\Delta \varepsilon_{i, j}=\varepsilon_{j}(\sigma)-\varepsilon_{i}(\sigma) ; j>i,
$$

where $\varepsilon_{\mathrm{k}}$ is the strain in the kth loading and $\mathrm{s}$ the applied stress. This function, called the strain difference function, represents mainly the difference of inelastic strain between the two cycles. A larger amount of microcracks are generated during the first loading than the second, and the relation of inelastic strain to applied stress in the second cycle is linearized, as expected from experimental results (e.g., Zoback and Byerlee, 1975) and from shear microfracturing models. Thus, the expected gradient change should be more easily discriminated in the strain difference functions than in the ordinary stress-strain relations. Yamamoto et al.

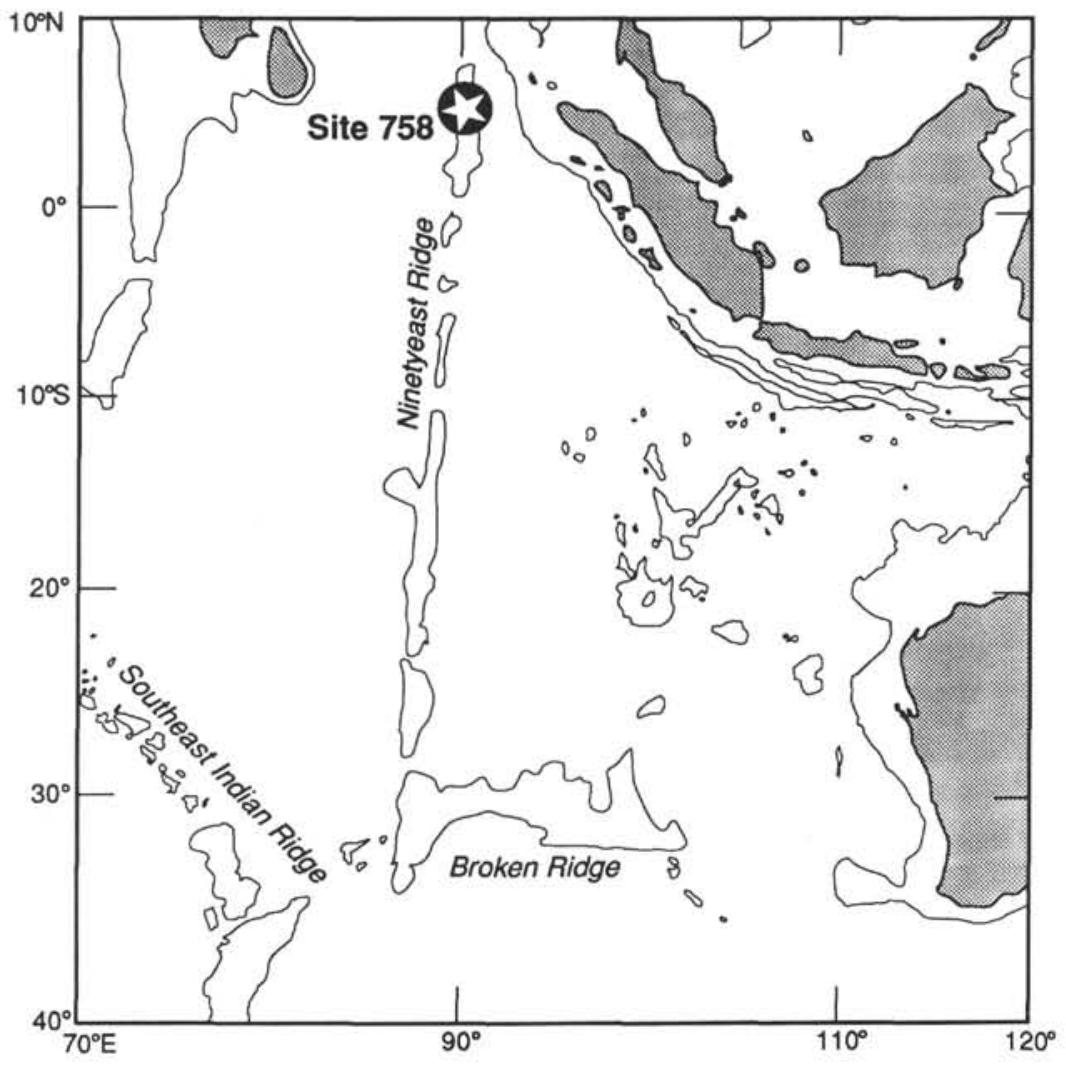

Figure 1. Location of Site 758 at the northern end of Ninetyeast Ridge. 
(1990) call this processing for the discrimination of the previous stress the deformation rate analysis (DRA).

\section{Hypothesis for In-Situ Stress Memory}

A rock is an aggregate of materials with different elastic constants. Respective component materials in a rock should generally be strained with different magnitudes by the same applied stress. These strains with different magnitudes may cause nonuniformities of strain and stress fields in the rock and produce stress concentrations near material boundaries, even when the applied stresses are hydrostatic. Stress concentration refers here to the nonuniform stress field which has potential to generate microscopic flow and/or microfracturing. In these statements, we implicitly assume a uniform stress field in the rock at the stress-free state.

In-situ stress is considered to be approximately constant with time. In unfractured rocks, the nonuniformities due to in-situ stress may be minimized after a long time by the change in shape of component materials due to the microscopic flow. We may assume that rocks are in the state of the least nonuniform stress field under in-situ stresses. Applying stress to a sample recovered from depth, we may express a component $\sigma^{\mathrm{a}} \mathrm{ij}$ of the applied stress as

$$
\sigma^{a_{i j}}=\sigma_{i j}+\sigma_{i j}
$$

where $\sigma^{\mathrm{s}} \mathrm{ij}$ and $\sigma^{\mathrm{v}} \mathrm{ij}$ are components of in-situ stress and of virtual stress, respectively. The memory of in-situ stress is assumed to be where $\sigma^{a_{i j}}$ is equivalent to $\sigma^{s_{i j}}$. Since we have assumed that the stress nonuniformity in the sample is minimum at $\sigma^{\mathrm{a}} \mathrm{ij}$ equal to $\sigma_{\mathrm{ij}}^{\mathrm{s}}$, the amount of inelastic strain of the sample due to the stress concentration should depend on the amount of $\sigma^{\mathrm{v}} \mathrm{ij}$.

Inelastic strain of rocks under uni- and triaxial compression increases with an increase in the difference between axial stress and confining pressure. The inelastic strain due to this stress difference is called the first-mode inelastic strain. An increase in the first-mode strain is considered to lead the specimen to its fracturing. The inelastic strain related to the in-situ stress memory is called the second-mode inelastic strain. We assume here that inelastic strain of a specimen under uni- and triaxial compression consists of the inelastic strains of these two modes, although inelastic strain may be generated by sources other than the two mentioned. If the first-mode strain is small, or if it linearly increases with an increase in applied stress, we should be able to easily discriminate the gradient change in the strain difference functions at the applied stress where the second-mode strain begins to increase with an increase in applied stress.

\section{Application of the DRA to In-situ Stress Estimation}

Using the DRA, Yamamoto et al. (1990) measured the previous stresses of boring core samples of granodiorite at sub-bottom depths less than about $143 \mathrm{~m}$. They found that the azimuthal distribution of the peak horizontal previous stresses observed for the core samples satisfy the theoretical requirements for stress fields and that the vertical stresses are nearly equal to the overburden pressures in magnitude. From these findings, they concluded that the magnitudes of the previous peak stresses of cores can be regarded as those of the in-situ stresses or the memory of in-situ stresses. They also found that the in-situ stress memory is often observed in the strain difference functions obtained from pairs of loading cycles later than the first cycle under cyclic loading tests and that the memory once again appears by repeating the DRA about a week after the first measurement.
The in-situ stresses estimated by the DRA have been compared with those by an overcoring method (OC) at two sites. At one site, the maximum and the minimum stresses were estimated to be $2.0 \pm 0.1$ and $0.8 \pm 0.1 \mathrm{MPa}$ at the depth of $17-21 \mathrm{~m}$ by the DRM and 2.3 and $0.0 \mathrm{MPa}$ at a depth of $11 \mathrm{~m}$ by the OC. The directions of the maximum or the minimum horizontal stresses differed by about $10^{\circ}$ between the two methods (Koide et al., 1986). The other site is in an unused quarry where a 40-m-high portion of a hill was cut out. Yamamoto et al. (1986) compared the results of the DRA with those of the OC by Koide et al. (1981) at this site. The maximum and the minimum stresses are $3.9 \pm 0.2$ and $2.1 \pm 0.2 \mathrm{MPa}$ at the depth of $12.0-12.8 \mathrm{~m}$ by the DRA, respectively, and 3.88 and $2.21 \mathrm{MPa}$ at $19.4 \mathrm{~m}$ depth by the OC. The azimuth of the maximum compression was identically determined with an error of $\pm 4^{\circ}$. The vertical stress was estimated only by the DRA at $1.7 \pm 0.1 \mathrm{MPa}$. This magnitude is too large for that of the overburden pressure at the depth. Although these comparisons have been carried out only for very shallow depths, the results indicated that the DRA can be a useful tool for in-situ stress estimation.

Yamamoto et al. (1989) examined the depth dependence of the vertical previous stress of core samples measured by the DRA. Their examination is as follows: the core samples used are quartz diorites, granodiorites, porphyrites, siliceous sandstones, and siliceous slates. Their wet bulk densities range from about 2.64 to $2.77 \mathrm{~g} / \mathrm{cm}^{3}$. The Young's moduli are between about 40 and 78 $\mathrm{GPa}$. The strain difference functions defined by equation (1) were obtained by a procedure similar to that explained in the next section. Examples of the functions obtained are shown in Figure 2 for four specimens at $376 \mathrm{~m}$ in depth and for two at $705 \mathrm{~m}$ in depth. The specimens from $376 \mathrm{~m}$ are siliceous sandstone and those of $705 \mathrm{~m}$ are siliceous slate. The overburden pressures are roughly estimated at 9.7 and $19 \mathrm{MPa}$ for the respective depths. As seen in the figures, the folding points of the functions can be found for all specimens near the axial stresses equal in value to the estimated overburden pressures. Such axial stresses of the bending points, regarded as the vertical previous stress, are plotted in Figure 3 as a function of depth. This relation shows that the value of the vertical previous peak stress is regarded as that of the overburden pressure for a wide range of the stress magnitudes and is independent of the magnitudes of other in-situ stress components. One of their conclusions is that the magnitude of the previous peak stress can be taken as that of in-situ stress for any stress ranges. The other is that the memory of in-situ stress is observable not only in granitic rocks but also in sedimentary rocks.

\section{PROCEDURE OF STRESS MEASUREMENTS}

We collected basaltic sample cubes from three depths between 502 and $639 \mathrm{~m}$ below seafloor (mbsf) at Hole 758A in a water depth of about $2924 \mathrm{~m}$ (Fig. 4). The samples used in this experiment are 121-758A-55R-2, 122-133 cm, 121-758A-64R-1, 1-6, 94-96 cm, and 121-758A-69R-5, 36-47 cm. At least three cubes were collected from single core pieces at each depth; two cubes were taken such that the split surface of the working half of the core formed one side and the other cube has surfaces rotated $45^{\circ}$ or $30^{\circ}$ horizontally from the split surface of the core. Remanent magnetization was measured for all the cubes before the stress measurements. One of the cube samples cut parallel to the split surface of the core was used to obtain measurements of vertical stress. Densities of these samples are between 2.67 and 2.76 $\mathrm{g} / \mathrm{cm}^{3}$, and $P$-wave velocities are between 4550 and $5000 \mathrm{~m} / \mathrm{s}$ (Shipboard Scientific Party, 1989). We weighed the specimens used for this experiment in air and in water after keeping the specimens in water for about 4 days to obtain the wet bulk 


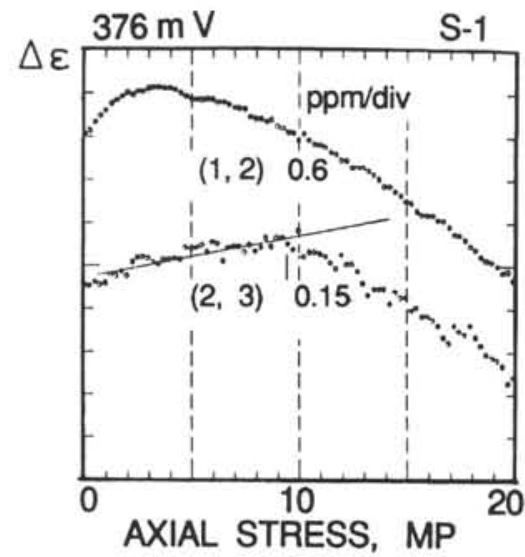

A

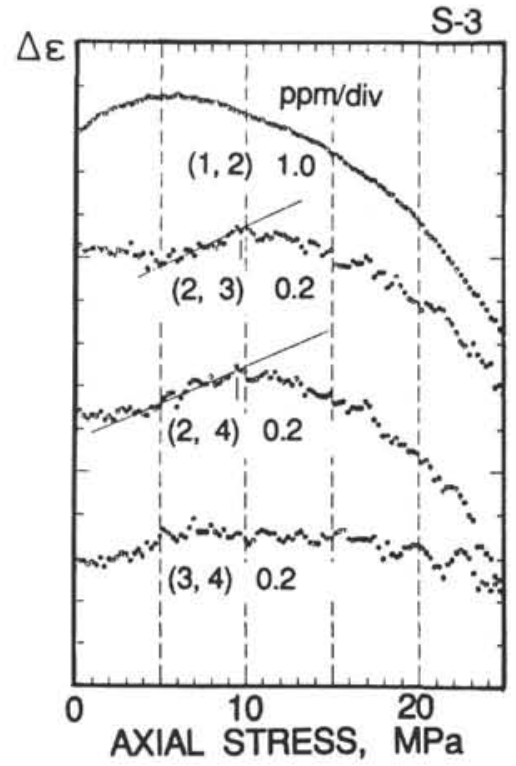

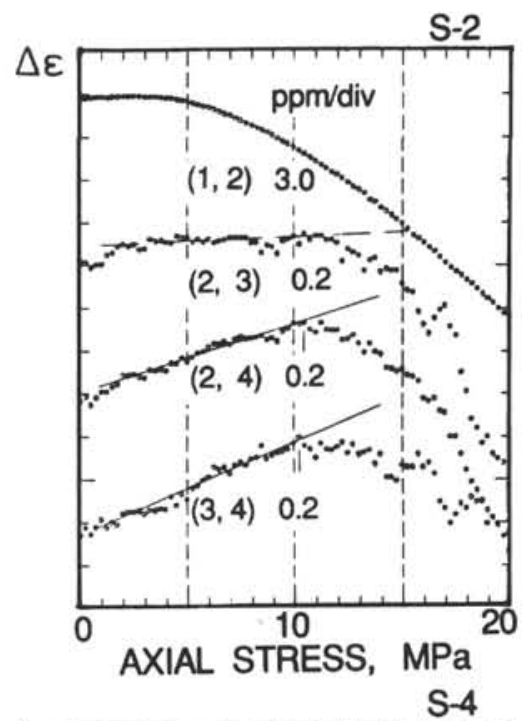

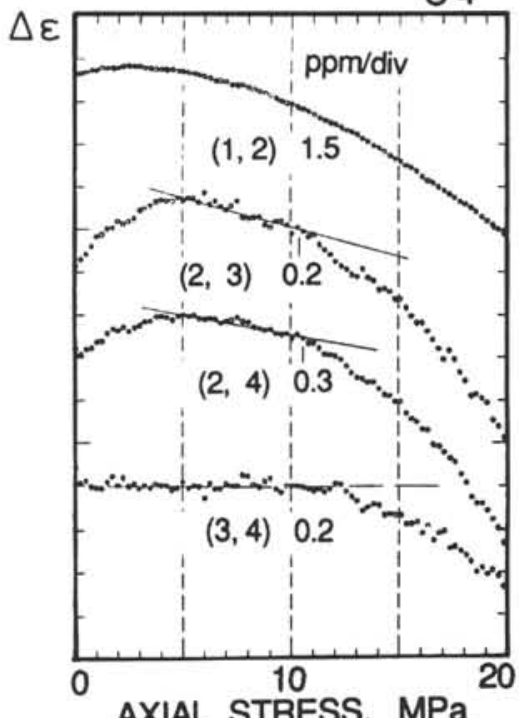

Figure 2. A. Strain difference functions $\Delta \varepsilon(\sigma)$ for specimens, $S-1$ to $S-4$, of siliceous sandstone at $376 \mathrm{~m}$ in depth. B. $\Delta \varepsilon(\sigma)$ for specimens, S-1 and S-2, of siliceous slate at $705 \mathrm{~m}$ in depth. Symbol $(\mathrm{i}, \mathrm{j})$ denotes the function obtained from the $\mathrm{i}^{\mathrm{th}}$ and the $\mathrm{j}^{\text {th }}$ loading. Sensitivity for the strain difference $\Delta \varepsilon$ is indicated in $10^{-6} /$ division (ppm/div) (after Yamamoto et al., 1989).

densities. The specimens were dried at about $60^{\circ} \mathrm{C}$ for about 24 $\mathrm{hr}$ in a vacuum vessel to obtain the dry bulk densities. The densities thus obtained are listed in Table 1 together with the porosities and the grain densities. The porosities and the grain densities are calculated from the dry and wet bulk densities.

We sawed four specimens from each cubic sample for stress measurement. Each specimen is a rectangular prism in shape and about $10 \mathrm{~mm} \times 10 \mathrm{~mm} \times 20 \mathrm{~mm}$ in size. The previous peak stress was measured in the direction of the longest axis, which is vertical to the split-core surface in the case of the horizontal stress measurement. The stress measurements were performed by the procedure similar to that presented by Yamamoto et al, (1990). The loading system and strain gauge placement are schematically illustrated in Figure 5. In order to measure the previously applied stress, uniaxial compressional loading was cycled six times for each specimen, with some exceptions of five cycles (Fig. 6). The loading was performed at a constant stress rate by a servo-controlled apparatus. The peak value of the applied stress was set as a constant for any cycles during each measurement. The peak applied stress values were in the range of 40 to $60 \mathrm{MPa}$ and the stress rate is between 3.3 and $4.0 \mathrm{MPa} / \mathrm{min}$. The peak stress should be chosen so that the stress is larger in value than the previous peak, or in-situ, stress to be obtained and that the first mode inelastic strains generated are as small as possible.

We abbreviate here the strain difference function $\Delta \varepsilon_{\mathrm{i}, \mathrm{j}}(\sigma)$ defined by equation (1) as $(i, j)$ for simplicity. Contraction and compression are defined to be positive in sign. A negative gradient of the function indicates that the increase in inelastic strain rate is larger in the ith cycle than in the jth cycle. Thus, the increase in the inelastic strain rate generated in the ith cycle should be observed as a negative gradient change of the function. In order to measure the strain difference with resolution as high as possible, we made a difference between the output of strain gauges and that of load cell and amplified it about five times with an amplifier with accuracy of about $2 \%$. We call this difference the reduced strain. This procedure depresses the high-frequency changes in the reduced strain, because the strain caused by the high frequency of stress application due to servo-controlled appa- 


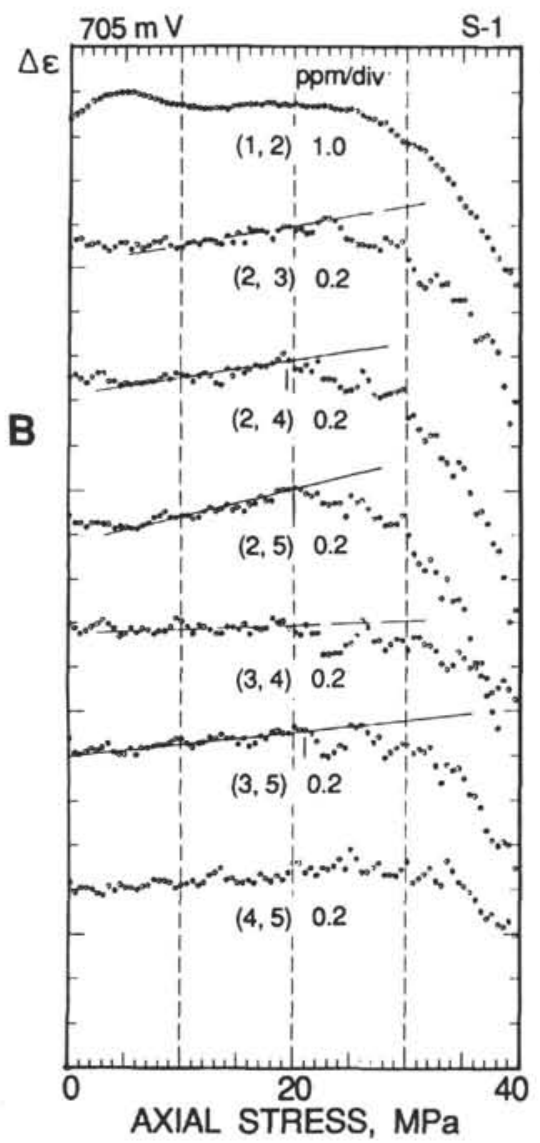

Figure 2 (continued).

ratus are more or less elastic. An example of the stress-strain curve and the reduced stress-strain curve are shown as an example in Figure 7. These results were obtained from the vertical specimen, S-2, of Sample 121- 758A-55R-2, 122-133 cm.

All the data of $\Delta \varepsilon_{i, j}(\sigma)$ from sets of successive loading cycles are shown in Figure 8 for the two vertical specimens from the sample of Core 121-758A-55R. The functions $(1,2)$ show a large nonlinear behavior for $\mathrm{S}-1$ and $\mathrm{S}-2$ specimens. Such nonlinearities are common for each specimen. For this reason, we used the functions, $(i, i+1)$ with some exceptions $(i, i+2)$ from the cycles later than the first cycle for discriminating and determining the magnitude of the previous peak stresses.

\section{RESULTS OF GEOMAGNETIC MEASUREMENTS}

Remanent magnetization was measured on Schonstedt spinner magnetometers (SSM-1A and DSM-2), and alternating field demagnetization was carried out on a Schonstedt two-axis tumbler demagnetizer (GSD-5) with a maximum AF-field of $100 \mathrm{mT}$. To check magnetic stability, a laboratory storage test was performed on selected samples (Figs. 9A-B). During $10^{7} \mathrm{~s}$ of exposure in the present geomagnetic field, samples have acquired the viscous remanent magnetization (VRM) equivalent intensity of the initial NRM. The results of the storage tests show that the stability of magnetic samples at Site 758 is not great which may lead to some ambiguity in determining the original remanent vector.

In order to determine the horizontal direction of the cut surface, optimal declination of each sample was examined by the Zijderveld projection of step demagnetization. Declinations obtained by the Zijderveld projection are plotted on an orthogonal plane after correction of the orientation of cubic samples. Figures

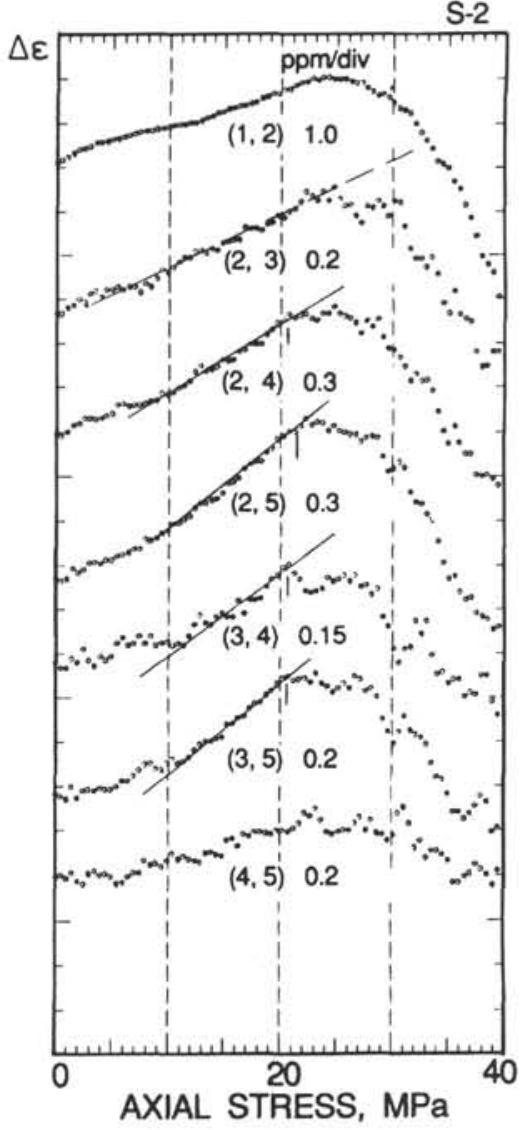

$10 \mathrm{~A}-\mathrm{C}$ show directions of the cutting surface against the Earth's paleo-coordinates.

Optimal declinations of Samples 121-758A-55R, 125-127 cm and $121-758 \mathrm{~A}-69 \mathrm{R}, 36-38 \mathrm{~cm}$ seem to be unique directions of $255^{\circ}$ and $245^{\circ}$, respectively. On the other hand, optimal declination of samples from Core 121-758A-64R cannot be precisely determined. Because most magnetic minerals in these samples seem to be secondarily produced by the alteration of rocks, these declinations are not directions against the present coordinates of the Earth, but represent the directions present when the crustal section at this site was formed in the Campanian.

\section{RESULTS OF STRESS MEASUREMENTS}

\section{Vertical Stresses}

The vertical stresses were measured on the paired specimens S-1 and S-2 (Fig. 8) at each of three depths for Samples 121-758A$55 \mathrm{R}, 125-127 \mathrm{~cm},-64 \mathrm{R}, 1-3 \mathrm{~cm}$, and $-69 \mathrm{R}, 36-38 \mathrm{~cm}$. Up to 50 $\mathrm{MPa}$ of uniaxial compressional stress was applied to one of the specimens and up to $60 \mathrm{MPa}$ to the other, in order to confirm that the folding point does not change with the change in the peak value of applied stress.

All the data of the strain difference function $\Delta \varepsilon_{i, j}(\sigma)$ or $(i, j)$ for the vertical specimens S-1 and S-2 of Sample 121-758A-55R, $125-127 \mathrm{~cm}$, are shown in Figure 11A. The traces of $(\mathrm{i}, \mathrm{j})$ are seen to show large nonlinear behavior. Without information about the in-situ stress at the depth, we may not uniquely identify the previous stress from these data because of the large nonlinearity. However, we fortunately know from the sampling depths that the overburden pressures are more than the water pressure of about 


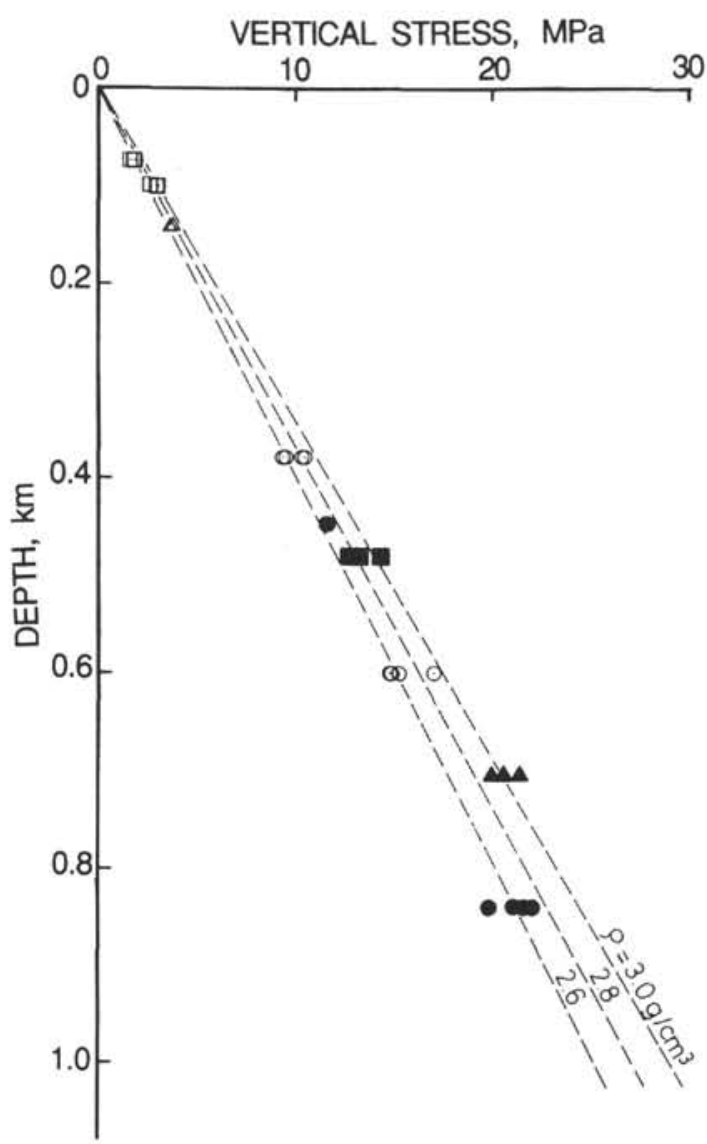

Figure 3. Relation between sampling depth and vertical stress magnitude obtained by the deformation rate analysis (DRA). Straight lines correspond to average densities of overburden rocks of $2.6,2.8$, and $3.0 \mathrm{~g} / \mathrm{cm}^{3}$, respectively. The same symbol indicates the same sampling site (after Yamamoto et al., 1989).

$34 \mathrm{MPa}$ at these depths. With this information, and assuming that the vertical previous stresses of the specimens at about the same depth are nearly the same, we picked from each set of strain difference functions one of the applied stresses at which the gradient change of $\Delta \varepsilon_{i, j}(\sigma)$ is relatively large and considered it as the magnitude of the previous peak stress. The data points at which the magnitudes of the previous peak stress were read are marked with arrows in Figure $11 \mathrm{~A}$. We did not include a magnitude if it differed more than roughly $10 \%$ from the mean of the other determined magnitudes. The average of stress magnitude thus estimated is $34.5 \pm 1.2 \mathrm{MPa}$. The standard deviation is about $3.5 \%$ of the average. The representative data of $\Delta \varepsilon_{i, j}(\sigma)$ are shown in Figure 11B for the vertical specimens of Cores 121-758A-64R and $-69 \mathrm{R}$. The observed stresses are 35.5 and $37.6 \pm 0.4 \mathrm{MPa}$ in magnitude for Cores 121-758A-64R and $-69 \mathrm{R}$, respectively.

We can see that traces of $(i, j)$ for almost of all vertical specimens bend at applied stresses between 20 and $30 \mathrm{MPa}$. These values of applied stress cannot be adopted as the vertical stress magnitudes, because they are too small to be regarded as those of the vertical stress. A test specimen sawed from Section 121-758A58R-3 fractured near $45 \mathrm{MPa}$ of the axial stress. Inferring from this stress, and from the behavior as described below of the strain difference function $(5,6)$ for the specimen S-2 of Section 121$758 \mathrm{~A}-64 \mathrm{R}-1$, the specimens tested here probably have strengths not much larger than $60 \mathrm{MPa}$. The applied stresses for bending are considered to be near $30 \%-50 \%$ the strengths of the speci- mens. Paterson (1978) pointed out that the stress level for the onset of dilatancy is usually observed to be between one-third and two-third of the strength. Thus, the stresses for bending are high enough to produce remarkable inelastic strain increases of the first mode defined in the previous section. For this reason, we interpret that bending at lower applied stresses is caused by an increase in the first-mode strain.

We cannot find the clear gradient change in any traces of $(i, j)$ for the specimen S-2 of Section 121-758A-64R-1. The amplitude of the strain difference change of $(5,6)$ is larger than that of $(4$, 5 ) and is two or three times as large as those for other specimens. We interpret this behavior to indicate that a remarkable amount of creep, leading to the eventual fracture of the specimen, occurred in the fifth loading. We cannot observe such behavior of $(5,6)$ for the specimen S-1 of Section 121-758A-64R-1. The Young's modulus of the specimen S-2 is about $25 \mathrm{GPa}$ for applied stresses less than $15 \mathrm{MPa}$. This value is nearly equal to about 23 $\mathrm{GPa}$ for the specimen $\mathrm{S}-1$. We have no reason to consider that the strength of the specimen S-2 is smaller than that of specimen S-1. The peak value of stress applied to the specimen $\mathrm{S}-2,60 \mathrm{MPa}$, is so close to the strength of the specimen as to damage it, and hence the gradient change due to the previous stress is buried in the larger nonlinear change in the first mode inelastic strain.

\section{Pore Pressure Effect}

The magnitude of the vertical in-situ stress at a depth should be taken approximately as the overburden pressure. We compared the measured vertical stresses with the overburden pressures calculated from densities of overburden rocks and depths to confirm that the measured previous stress can be regarded as the in-situ stress. Using all data of wet bulk density of cores measured by Shipboard Scientific Party (1989), we calculated the overburden pressures at the corresponding depths for Samples 121-758A$55 \mathrm{R}-2,125-127 \mathrm{~cm},-64 \mathrm{R}-1,1-3 \mathrm{~cm}$, and $-69 \mathrm{R}-5,36-38 \mathrm{~cm}$. The overburden pressures thus obtained are about $37.5,39.6$, and 40.8 $\mathrm{MPa}$, for respective depths. These values are larger by 3.0, 4.1, and $3.2 \mathrm{MPa}$ than those of the measured vertical stress, respectively. Even though the error of 5\% in the measured values is taken into consideration, the observed stress is significantly less than the calculated overburden pressure. Referring to the porosity data in Table 1, we can see that the difference is the largest for the sample with the largest porosity. The smaller values of the measured vertical stress may be caused by pore pressures, which are not accounted for in the stress measurements done in the laboratory.

Average stresses $\sigma^{\mathrm{av}} \mathrm{ij}$ in a composite material depend only on the surface tractions at the bounding surface of the material independently of the constitutive relation or the internal structure of the material (e.g., Hill, 1963; Watt et al., 1976). Thus, the average stress in rocks, that is the in-situ stress, may be expressed without any constraints as

$$
\sigma^{\mathrm{av}} \mathrm{ij}=\phi_{\mathrm{sl}} \cdot \sigma^{\mathrm{sl}} \mathrm{ij}_{\mathrm{j}}+\phi^{\mathrm{pr}} \cdot \sigma^{\mathrm{pr}} \cdot \delta_{\mathrm{ij}}
$$

where $\phi_{\mathrm{sl}}$ and $\phi_{\mathrm{pr}}$ are the volume fractions of the solid part and of the liquid part, respectively, $\sigma^{\mathrm{s}} \mathrm{ij}_{\mathrm{ij}}$ and $\sigma^{\mathrm{pr}}$ are components of the average stress in the solid part and the pore pressure, $\delta_{i j}$ is Kronecker's delta. Since the pore pressure is not a factor during stress measurements, the stress to be measured corresponds to the first term of the right-hand side of equation (3). Assuming that all pores are interconnected with one another, the in-situ pore pressure is equal in value to the water pressure at the depth. Using the porosity in Table 1, the values of the second term are estimated to be about $3.3,5.1$, and $3.6 \mathrm{MPa}$, respectively, for Samples 121-758A-55R-2, 125-127 cm, -64R-1, 1-3 cm, and -69R-5, $36-38 \mathrm{~cm}$. These values are found to be quite close to those of the 


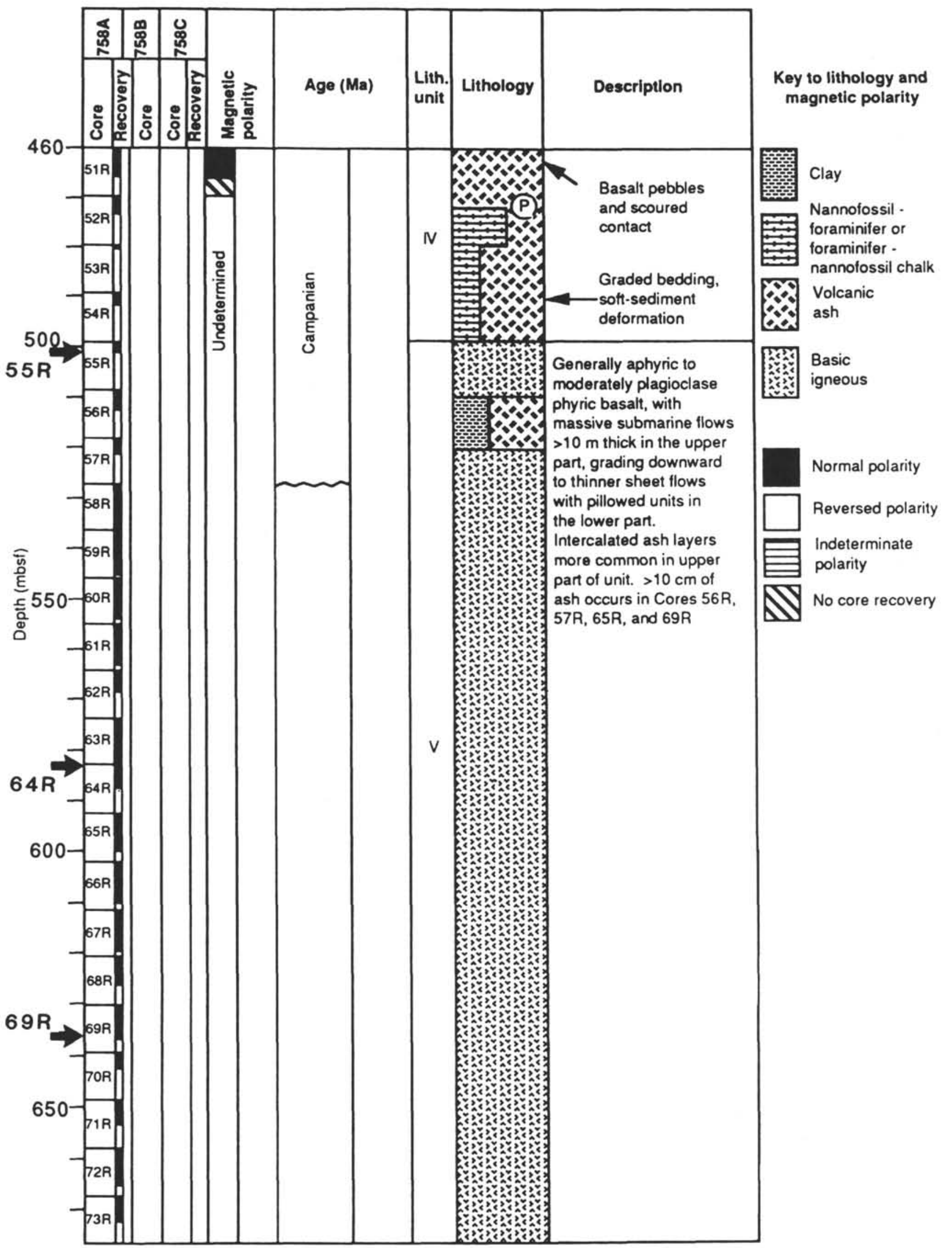

Figure 4. Sample location geology; Hole 758A. 
Table 1. Physical properties of cores used for the measurements.

\begin{tabular}{ccccc}
\hline Sample & $\begin{array}{c}\rho_{\mathrm{w}} \\
g / \mathrm{cm}^{3}\end{array}$ & $\begin{array}{c}\rho_{\mathrm{a}} \\
g / \mathrm{cm}^{3}\end{array}$ & $\begin{array}{c}\rho_{\mathrm{g}} \\
g / \mathrm{cm}^{3}\end{array}$ & $\begin{array}{c}\phi \\
q\end{array}$ \\
\hline $121-758 \mathrm{~A}-55 \mathrm{R}-2,125-127 \mathrm{~cm}$ & 2.740 & 2.641 & 2.93 & 9.9 \\
$121-758 \mathrm{~A}-64 \mathrm{R}-1.1-3 \mathrm{~cm}$ & 2.680 & 2.531 & 2.97 & 14.9 \\
$121-758 \mathrm{~A}-69 \mathrm{R}-5.36-38 \mathrm{~cm}$ & 2.749 & 2.647 & 2.95 & 10.2
\end{tabular}

Note: $\rho_{w}=$ Wet bulk density, $\rho_{a}=$ Dry bulk density, $\rho_{g}=$ grain density, $\phi=$ porosity.

difference between the measured vertical stress and the calculated overburden pressure. We can thus interpret that the measured magnitudes of the vertical stress correspond to the average stress of the solid part and that the smaller magnitudes obtained by the DRA are caused by the pore pressure effect. The vertical stresses corrected with the estimated values of the second term are 37.8 , 40.6 , and 41.2 MPa for Samples 121-758A-55R-2, 125-127 cm, $-64 \mathrm{R}-1,1-3 \mathrm{~cm}$, and $-69 \mathrm{R}-5,36-38 \mathrm{~cm}$, respectively. Comparing these magnitudes with those of the calculated overburden pressure, the differences are less than $3 \%$ in the largest case. The magnitudes of pore pressure effects are considered to be the same for horizontal stress determinations as for vertical stress.

\section{Horizontal Stresses}

Azimuthal distribution of in-situ stress was estimated from the previous stress in the four azimuthal directions. The stress in each azimuthal direction was measured on paired specimens for each depth. The peak value of the applied stress was set at a value between 40 and $60 \mathrm{MPa}$, approximately, according to the stiffness of the specimen. The representative data for the horizontal specimens of for Samples 121-758A-55R-2, 125-127 cm, -64R-1, 1-3 $\mathrm{cm}$, and $-69 \mathrm{R}-5,36-38 \mathrm{~cm}$, respectively, are shown in Figures $11 \mathrm{~A}-\mathrm{C}$. We see that the traces of $(\mathrm{i}, \mathrm{j})$ are extremely nonlinear and that many traces have relatively prominent bends around two values of applied stress, the lower is between $15 \mathrm{MPa}$ and $25 \mathrm{MPa}$ and the higher of the stresses is larger than about $25 \mathrm{MPa}$.

If the bending points are caused by the horizontal previous stresses, the azimuthal dependence of the stresses at which the bending occurs should be expressed by a sinusoidal function of azimuth with a period of $180^{\circ}$. We can see that the stress corresponding to the bends at higher stresses depends on the azimuth. As to the specimens of Sample 121-758A-55R-2, 125-127 cm, in Figure $11 \mathrm{~A}$, for example, the stresses of the relatively clear bending point are smaller than $30 \mathrm{MPa}$ in the direction of $\mathrm{F} 0^{\circ} \mathrm{E}$ but more than $30 \mathrm{MPa}$ in the direction of $\mathrm{F} 90^{\circ} \mathrm{E}$, even though the data are obtained from the specimens of the same cubic sample.
Furthermore, the changes in slope are observed near $25 \mathrm{MPa}$ in axial stress for $\mathrm{F} 45^{\circ} \mathrm{E}$ and more than $30 \mathrm{MPa}$ for $\mathrm{F} 135^{\circ} \mathrm{E}$; the specimens for this pair of directions were also retrieved from the same sample, too. As a whole, we can see that the axial stresses for the bending points show an azimuthal distribution of a period of $180^{\circ}$, which have the maximum between $\mathrm{F} 90^{\circ} \mathrm{E}$ and $\mathrm{F} 135^{\circ} \mathrm{E}$ and the minimum between $\mathrm{F} 0{ }^{\circ} \mathrm{E}$ and $\mathrm{F} 90^{\circ} \mathrm{E}$. The similar azimuthal dependence for the curve inflections at higher stresses are observable also for Samples 121-758A-64R, 1-3 cm, and -69R, 36-38 $\mathrm{cm}$. We thus adopt the stresses for the inflections at higher stresses as the previous stresses corresponding to in-situ stresses. The data points where the previous stress was determined are marked with arrows in Figure 11. These determinations were done in a similar manner as that for the vertical stress.

The magnitudes of previous stress obtained by the above procedure are plotted as a function of azimuth in Figures $12 \mathrm{~A}-\mathrm{C}$ for Samples 121-758A-55R-2, 125-127 cm, -64R, 1-3 cm, and $-69 \mathrm{R}, 36-38 \mathrm{~cm}$. The previous peak stress thus obtained is interpreted as the normal component of the in-situ stress in the direction corresponding to the loading axis of the specimen as inferred from equation (2). The maximum and the minimum horizontal stresses at a given depth are determined from the sinusoidal function of azimuth with the period of $180^{\circ}$ fitted to the stressazimuth relation by a least squares method (Fig. 12). The magnitudes of the maximum and the minimum horizontal stresses thus obtained are $(33.3 \pm 0.6,23.5 \pm 0.6),(35.0 \pm 1.0,23.5 \pm 1.0)$, and $(37.0 æ 0.9,26.8 æ 0.9)$ in MPa for Samples 121-758A-55R-2, 125$127 \mathrm{~cm},-64 \mathrm{R}-1,1-3 \mathrm{~cm}$, and $-69 \mathrm{R}-5,36-38 \mathrm{~cm}$, respectively, and are listed together with the magnitudes of the vertical stresses in Table 2. These magnitudes of the horizontal stresses may be smaller than the actual magnitudes of in-situ stress by the same amounts as those for the vertical stresses for respective depths.

The maximum horizontal stress is found to be close to the vertical stress in magnitude for any depth, and the minimum stress is about $10 \mathrm{MPa}$ less than the maximum horizontal stress. The vertical stress being one of the principal stress directions, the ratio of the maximum shear stress to the normal stress is about 0.20 at the most. This value is reasonable as that for in-situ stress. The magnitudes of the vertical, and maximum, and the minimum horizontal stresses estimated at this site mean that the site is in the tensional field where the average stress is smaller than the lithostatic pressure.

\section{DISCUSSION AND SUMMARY}

We tried to measure the previous peak stresses on basalt samples from Hole 758A by a new method, the deformation rate analysis (DRA), in order to estimate in-situ stress direction and magnitude at the northern end of Ninetyeast Ridge. Nine cubic

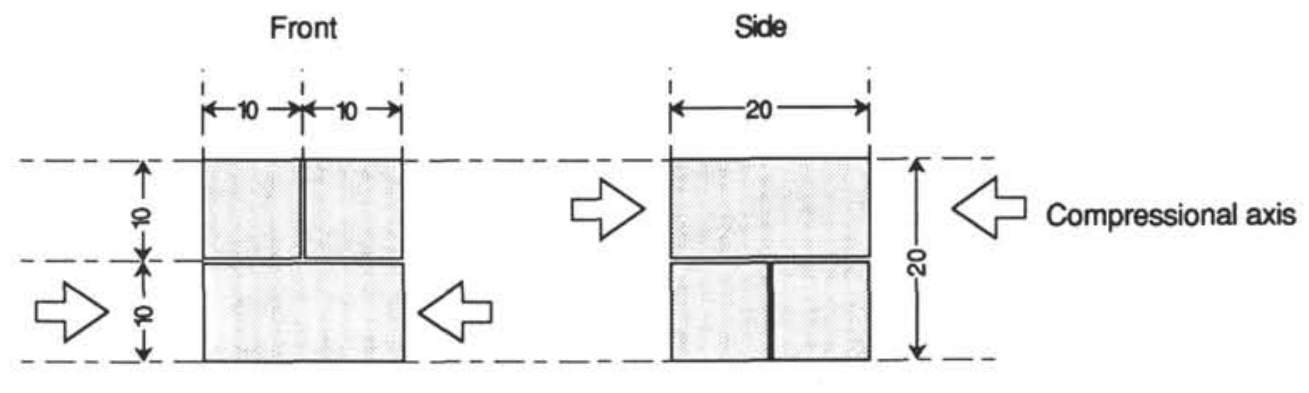

\section{Cubic sample $(\mathrm{mm})$}

Figure 5. Sample preparation for horizontal stress measurement. Four samples were cut horizontally from the cube. 


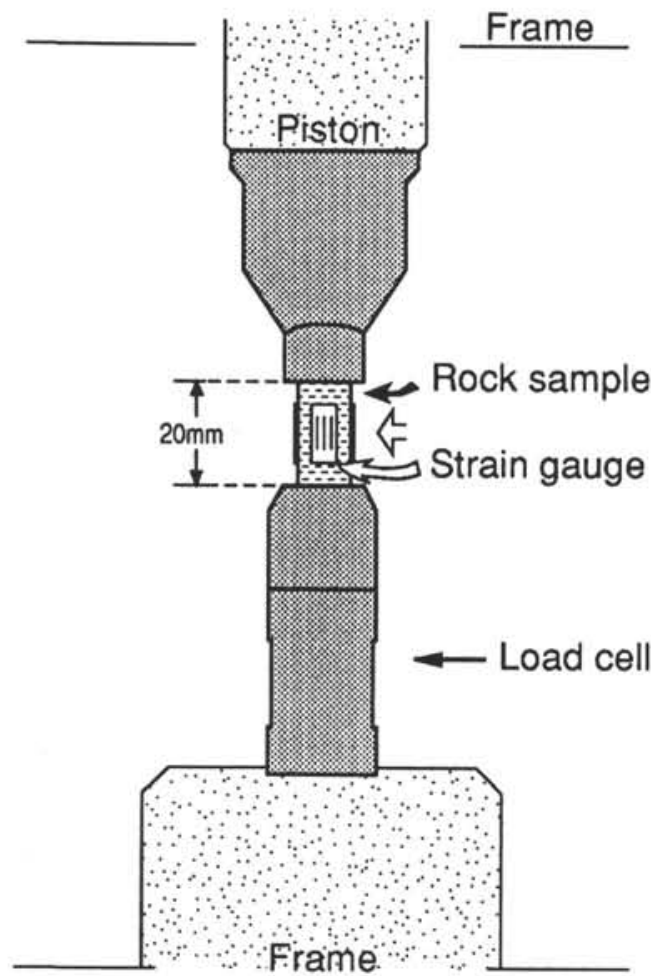

Figure 6. Sample loading system. Four strain gauges are pasted near the center of the free surfaces of the sample.

basalt samples recovered from three depths (Cores 121-758A$55 R,-64 R$, and $-69 R$ ) were measured, and the results are summarized in Table 3. Possible in-situ orientation of the samples was estimated from the declination of NRM magnetization of each sample with the probability that the NRM north may be shifted counterclockwise a maximum of $10^{\circ}$ due to the rotation of the Indo-Australian plate.

The measured value of previously applied peak stress in the vertical direction is about $37.8-41.2 \mathrm{MPa}$ of compression cor- rected for pore pressure effects; those in the horizontal plane range from about 26.8 to $37.0 \mathrm{MPa}$. The vertical stress has the same order of magnitude as the vertical in-situ stress estimated from the water depth and the sub-bottom depth of the samples, showing increasing value according to the sample depth. Using the azimuthal orientation of each sample obtained from the stable magnetization direction, the principal horizontal stresses are determined to be $36.6 \mathrm{MPa}$ in magnitude and approximately $\mathrm{N} 53^{\circ} \mathrm{W}$ in azimuth in Core 121-758A-55R, 40.1 MPa in magnitude and approximately $\mathrm{N} 6^{\circ} \mathrm{W}$ in azimuth in Core $121-758 \mathrm{~A}-64 \mathrm{R}$, and 40.6 $\mathrm{MPa}$ in magnitude and approximately $\mathrm{N} 37^{\circ} \mathrm{W}$ in azimuth in Core 121-758A-69R. All the above orientations are against the paleomagnetic north and may be shifted counterclockwise a maximum of $10^{\circ}$.

The obtained magnitudes of the previous peak stresses suggest that the maximum principal horizontal stress is nearly equal to the vertical stress in magnitude, and that the least principal stress is horizontal and slightly extensional (slightly less than the lithostatic stress). The results of paleomagnetic measurements of three or four cubes from each rock piece suggest that the orientation of horizontal stress axes, based on geomagnetic measurements, has an error of $\pm 5^{\circ}$ which probably comes from the deformation of rock core pieces after recovery from the drill hole. The error may be exaggerated in cases where the basement rocks suffered any rotational structural movement at the site.

The estimated orientations of horizontal in-situ stresses are not greatly different from the predicted regional stress field in the Indo-Australian plate boundary (Cloetingh and Wortel, 1986; Stein et al., 1989), as well as from two earthquake mechanism solutions at $97 \mathrm{nmi}$ north of Site 758 (Bergman and Solomon, 1985). The predicated regional stress field shows a north-northwest maximum horizontal compressional axis, and the earthquake mechanism solutions show $\mathrm{N} 11^{\circ} \mathrm{W}$ and $\mathrm{N} 31^{\circ} \mathrm{W}$ directions for maximum horizontal stresses. As Site 758 is close to the Sunda Trench, there may be some effect of bending lithosphere along the trench axis other than the regional stress regime. Further corroboration of our results was expected from analysis of borehole televiewer data obtained during Leg 121. Shore-based work following the cruise, however, determined that the borehole televiewer results were inconclusive (C. Wilkensen, pers.

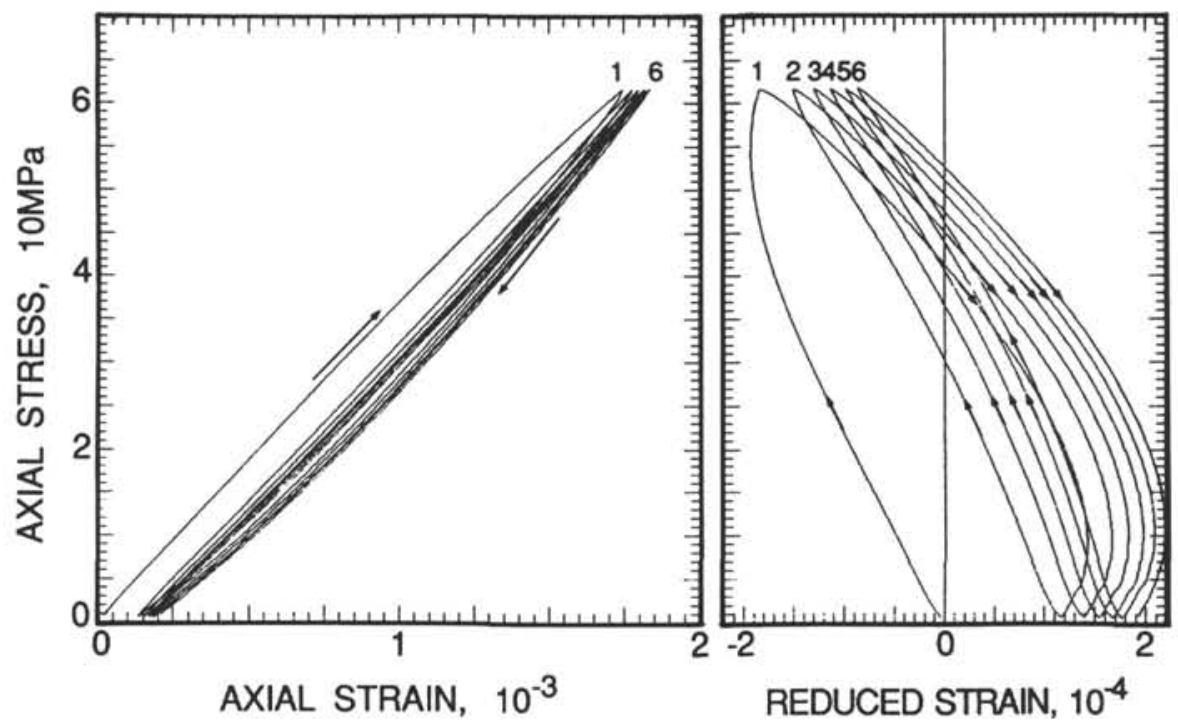

Figure 7. Stress-strain curves and reduced stress-strain curves for the vertical specimen, S-1, retrieved from Section 121-758A-55R-2. Numerals 1 to 6 indicate the cycle numbers of loading and unloading. The cycle numbers 2 to 5 in the stress-strain curves are omitted for clarity. Elapsed time is indicated by the direction of the arrows. 
S-1

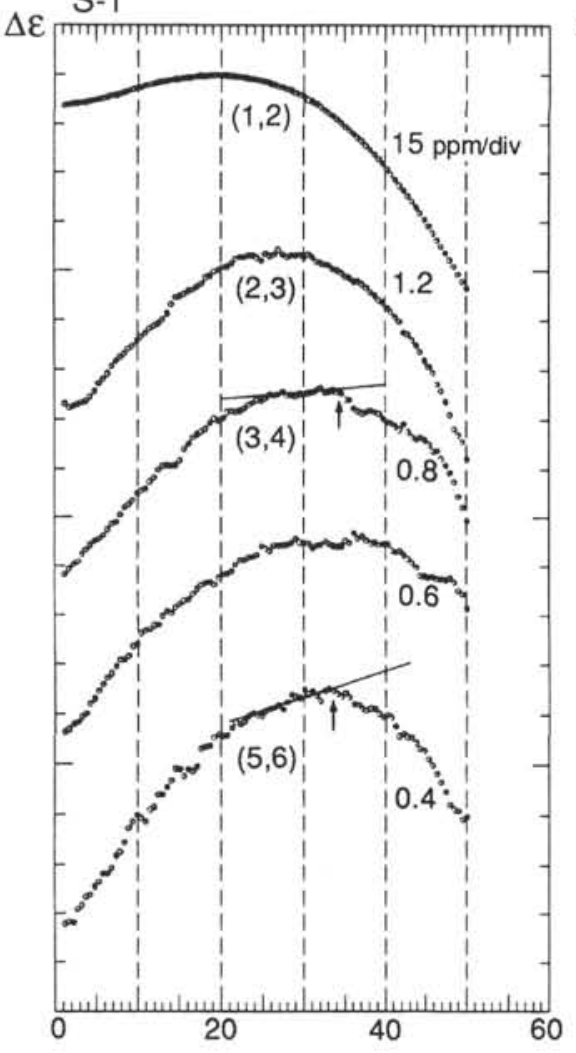

S-2

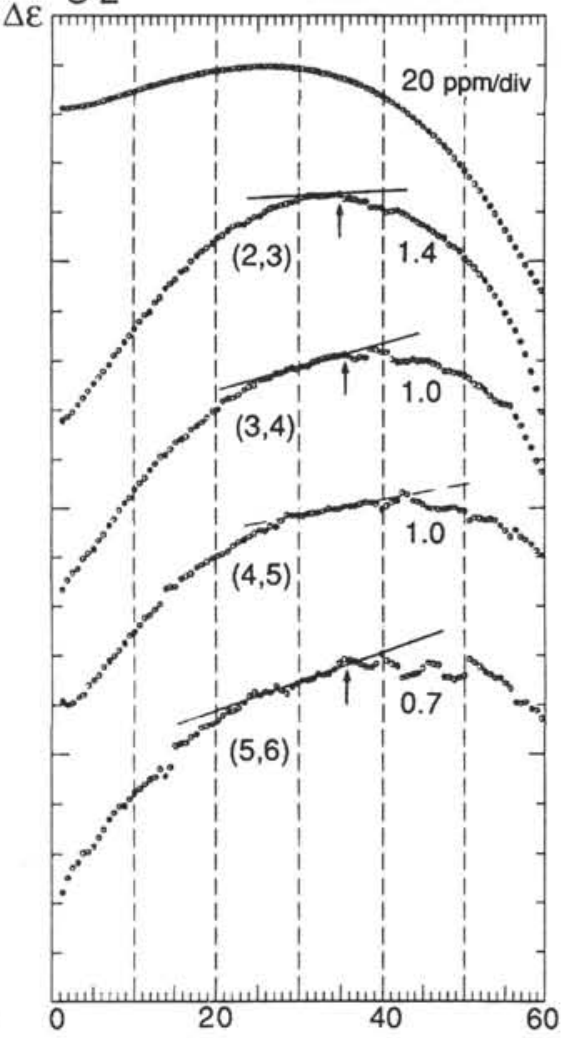

Axial stress (MPa)

Figure 8. A. Strain difference functions measured on the two vertical samples, S-1 and S-2, of Section 121-758A-55R-2. The symbol $(\mathrm{i}, \mathrm{j})$ means a set of $\mathrm{i}^{\text {th }}$ and $\mathrm{j}^{\mathrm{t} \text { h }}$ loading cycles used for driving the function. The functions from all sets of the successive cycles are shown. Arrows indicate the datum points at which the value of the axial stress was read as the magnitude of the previously applied peak stress. Sensitivity of the strain difference is labeled. B. Examples of the strain difference functions measured on the vertical samples of Sections 121-758A-64R-1 and 121-758A-69R-5. The symbols are same as those in Figure 9A.

comm.). However, we do not intend to discuss the details of the regional stress field based on our results, because the DRA method needs further sophistication of measurements and our estimated geographical orientation of the stress field may include unexaminable errors.

The DRA method has potential to be a useful tool for the estimation of in-situ stress, if we correctly identify the previous stress as well as in-situ orientation of samples. The DRA method needs more improvement in several aspects. One aspect is that the discrimination of the inflection points in the strain difference functions is difficult to determine when the function is largely curvilinear. We have two ways to improve this discrimination. One is as follows: if this curvilinearity is caused by the first-mode inelastic strain, as described in the preceding section, the curvilinearity should be reduced under confining pressures. The measurements under confining pressures are thus thought to be preferable, especially for the measurement of specimens of weak strength. The other to improve discrimination of the inflection point is to develop a statistical evaluation of the gradient change. This is being studied by some of the authors and others. In addition, there is a serious problem in that we must determine the peak value of applied stress before we know in-situ stress magnitudes, although this is a common problem for the methods of in-situ stress estimation. A better way for this method to be used is to be combined with other methods. Further experiments are necessary to validate this method for the estimation of in-situ stresses. We plan to apply the DRA method to basaltic samples recovered by ODP Leg 127 from the deep-sea basin basement of the Japan Sea.

\section{ACKNOWLEDGEMENTS}

The authors thank Yozo Hamano for discussion and Elliott Taylor for encouraging us. This paper benefitted from reviews by two anonymous reviewers. We thank them for many useful comments. The authors also thank Naoko Yasuzato, Keizo Sayanagi, and Yoshiko Kishida for their assistance of measurement of samples and processing of the data.

\section{REFERENCES}

Barton, C. A., and Zoback, M. D., 1988. Determination of in situ stress orientation from borehole guided waves. J. Geophys. Res., 93:78347844.

Bergman, E. A., and Solomon, S. C., 1985. Earthquake source mechanisms from body-waveform inversion and intraplate tectonics in the northern Indian Ocean. Phys. Earth Planet. Inter., 40:1-23.

Brace, W. F., Paulding, B. W., and Scholz, C., 1966. Dilatancy in the fracture of crystalline rocks. J. Geophys. Res., 71:3939-3953.

Cloetingh, S., and Wortel, R., 1986. Stress in the Indo-Australian plate. Tectonophysics, 132:49-67.

Hickman, S. H., Healy, J. H., and Zoback, M. D., 1985. In situ stress, natural fracture distribution, and borehole elongation in the Auburn Geothermal Well, Auburn, New York. J. Geophys, Res., 90:54975512 . 
121-758A-64R:Vertical

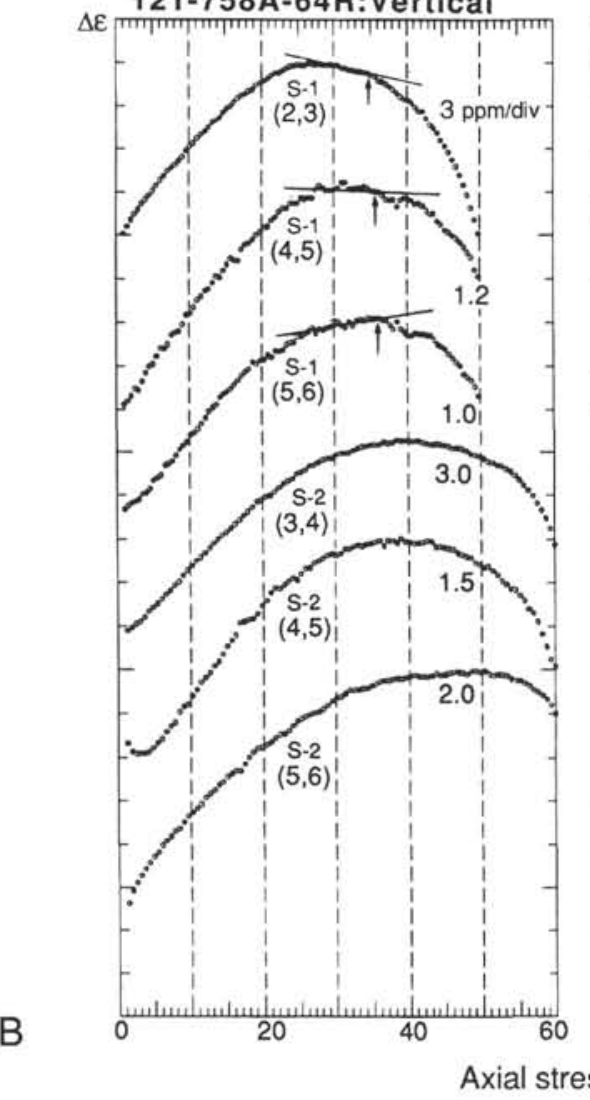

121-758A-69R:Vertical

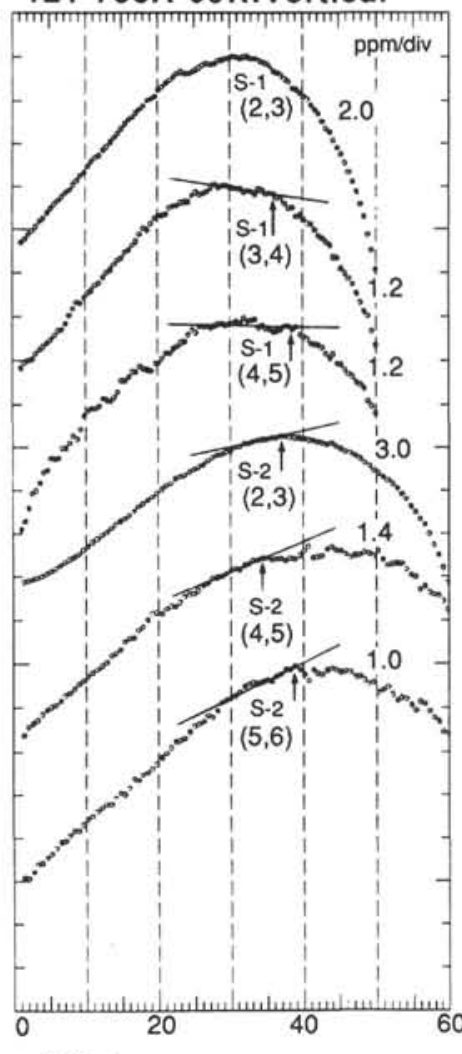

Figure 8 (continued).

Hill, R., 1963. Elastic properties of reinforced solids: some theoretical principles. J. Mech. Phys. Solids, 11:357-372.

Kanagawa, T., Hayashi, M., and Nakasa, H., 1977. Estimation of spatial geo-stress components in rock samples using the Keiser effect of acoustic emission. Proc. Jpn. Soc. Civ. Eng. 258:63-75. (in Japanese)

Koide, H., Hoshino, K., Kusunose, K., Inami, K., Nishimatsu, Y., Koizumi, S., and Akiyama, M., 1981. In situ stress measurement in Izu Shimoda area by overcoring. Progr. Abstr. Seism. Soc. Jpn. 1981, $2: 20$. (Abstract in Japanese)

Koide, H., Nishimatsu, Y., Koizumi, S., Hoshino, K., Kanagawa, T., Nakayama, Y., Inoue, A., Yamamoto, K., and Kikuchi, S., 1986. Comparison among several methods for stress measurement in the Kanto-Tokai district, Japan. Proc. 18th Jpn. Symp. Rock Mech., 261265. (in Japanese with English abstract)

Kuwahara, Y., Yamamoto, K., and Hirasawa, T., 1990. An experimental and theoretical study of inelastic deformation of brittle rocks under cyclic uniaxial loading. Tohoku Geophys. J. (Sci. Rep. Tohoku Univ., Ser. 5), 33:1-21.

McGarr, A., and Gay, N. C., 1978. State of stress in the Earth's crust. Annu. Rev. Earth Planet. Sci., 6:405-436.

Montgomery, C. T., and Ren, N.-K., 1981. Differential strain curve analysis: does it work? Proc. Workshop on Hydraulic Fracturing Stress Measurement: Monterey, CA, 239-245.

Morgan, W. J., 1981. Hotspot tracks and the opening of the Atlantic and Indian Oceans. In Emiliani, C. (Ed.), The Sea (Vol. 7): New York (Wiley), 443-487.

Newmark, R. L., Zoback, M. D., and Anderson, R. N., 1985. Orientation of in situ stresses near the Costa Rica Rift and Peru-Chile Trench, Deep Sea Drilling Project Hole 504B. In Anderson, R. N., Honnorez, J., Becker, K., et al., Init. Repts. DSDP, 83: Washington (U.S. Govt. Printing Office), 511-514.

Paterson, M. S., 1978. Dilatance. Experimental Rock Deformation-The Brittle Field: New York (Springer-Verlag), 114-120.

Ren, N.-K., and Roegiers, J. C., 1983. Differential strain curve analysisA new method for determining the pre existing in situ stress state from rock core measurements. Proc. 5th Congr. ISRM: Melbourne, F117F127.

Shipboard Scientific Party, 1989. Site 758. In Peirce, J., Weissel, J., Proc. ODP, Init.Repts., 121: College Station, TX (Ocean Drilling Program), 359-453.

Siegfried, R., and Simmons, G., 1978. Characterization of oriented cracks with differential strain analysis. J. Geophys. Res., 83:1269-1278.

Simmons, G., Siegfried, R. W., II, and Feves, M., 1974. Differential strain analysis: new method for examining cracks in rocks. J. Geophys. Res., 79:4383-4385.

Stein, C. A., Cloetingh, S., and Wortel, R., 1989. SEASAT-derived gravity constraints on stress and deformation in the northeastern Indian Ocean. Geophys. Res. Lett., 16:823-826.

Stevens, J. L., and Holcomb, D. J., 1980. A theoretical investigation of the sliding crack model of dilatancy. J. Geophys. Res., 85:7071-7100.

Strickland, F. G., and Ren, N.-K., 1980. Use of differential strain curve analysis in predicting in situ stress state for deep wells. Proc. 21 st $U$. S. Rock Mechanics Symp., Rolla, Missouri, 523-532.

Walsh, J. B., 1965. The effect of cracks on the compressibility of rock. J. Geophys. Res., 70:381-389.

Watt, J. P., Davies, G. F., and O'Connell, R. J., 1976. The elastic properties of composite materials. Rev. Geophys. Space Phys., $14: 541-563$.

Yamamoto, K., Kato, N., and Hirasawa, T., 1989. An interpretation of the previously applied stress obtained by deformation rate analysisdepth dependence of the vertical stress. Progr. Abstr. Seismol. Soc. Jpn. 1989, 1:44. (Abstract in Japanese)

Yamamoto, K., Kuwahara, Y., and Hirasawa, T., 1983. Discrimination of previously applied stress by the deformation rate analysis: application of the method to estimation of in situ stress. Progr. Abstr. of Seismol. Soc. Jpn. 1983, 2:104. (Abstract in Japanese)

Yamamoto, K., Kuwahara, Y., Kato, N., and Hirasawa, T., 1990. Deformation rate analysis: a new method for in situ stress estimation from inelastic deformation of rock samples under uni-axial compressions. Tohoku Geophys. J. (Sci. Rep. Tohoku Univ., Ser. 5), 33:127-147. 
Yamamoto, K., Kuwahara, Y., Kato, N., Hirasawa, T., and Koide, H., 1986. An experiment for estimation of in-situ stresses by deformation rate analysis. Progr. Abstr. of Seismol. Soc. Jpn. 1986, 2:230. (Abstract in Japanese)

Yoshikawa, S., and Mogi, K., 1981. A new method for estimation of the crustal stress from cored rock samples: laboratory study in the case of uniaxial compression. Tectonophysics, 74:323-339.

Zheng, Z., Kemeny, J., and Cook, N.G.W., 1989. Analysis of borehole breakouts. J. Geophys. Res., 94:7171-7182.
Zoback, M. D., and Byerlee, J. D., 1975. The effect of cyclic differential stress on dilatancy in Westerly granite under uniaxial and triaxial conditions. J. Geophys. Res., 80:1526-1530.

Zoback, M. D., Moos, D., Mastin, L., and Anderson, R. N., 1985. Wellbore breakouts and in situ stress. J. Geophys. Res, 90:5523-5530.

Date of initial receipt: 1 March 1990

Date of acceptance: 11 December 1990

Ms 121B-159 

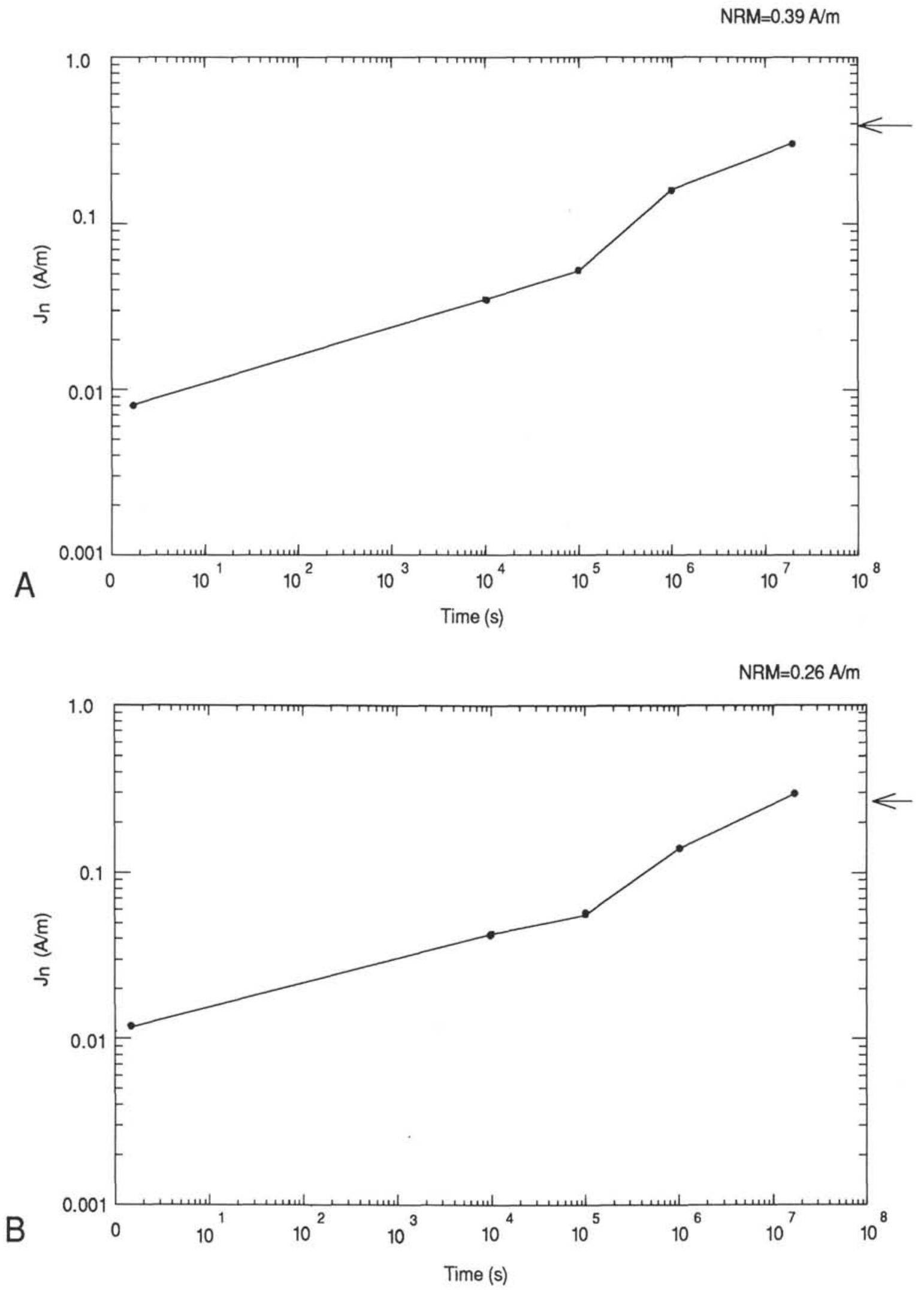

Figure 9. Effect of VRM for Samples 121-758A-69R-5, 36-38 cm (A) and 121-758A-69R-5, 42-44 cm (B). VRM seems to be obtained proportionally to exposed time in the geomagnetic field. Terminal VRM's (approximately 210 days) in the storage test become equivalent to the initial NRM (arrow). 


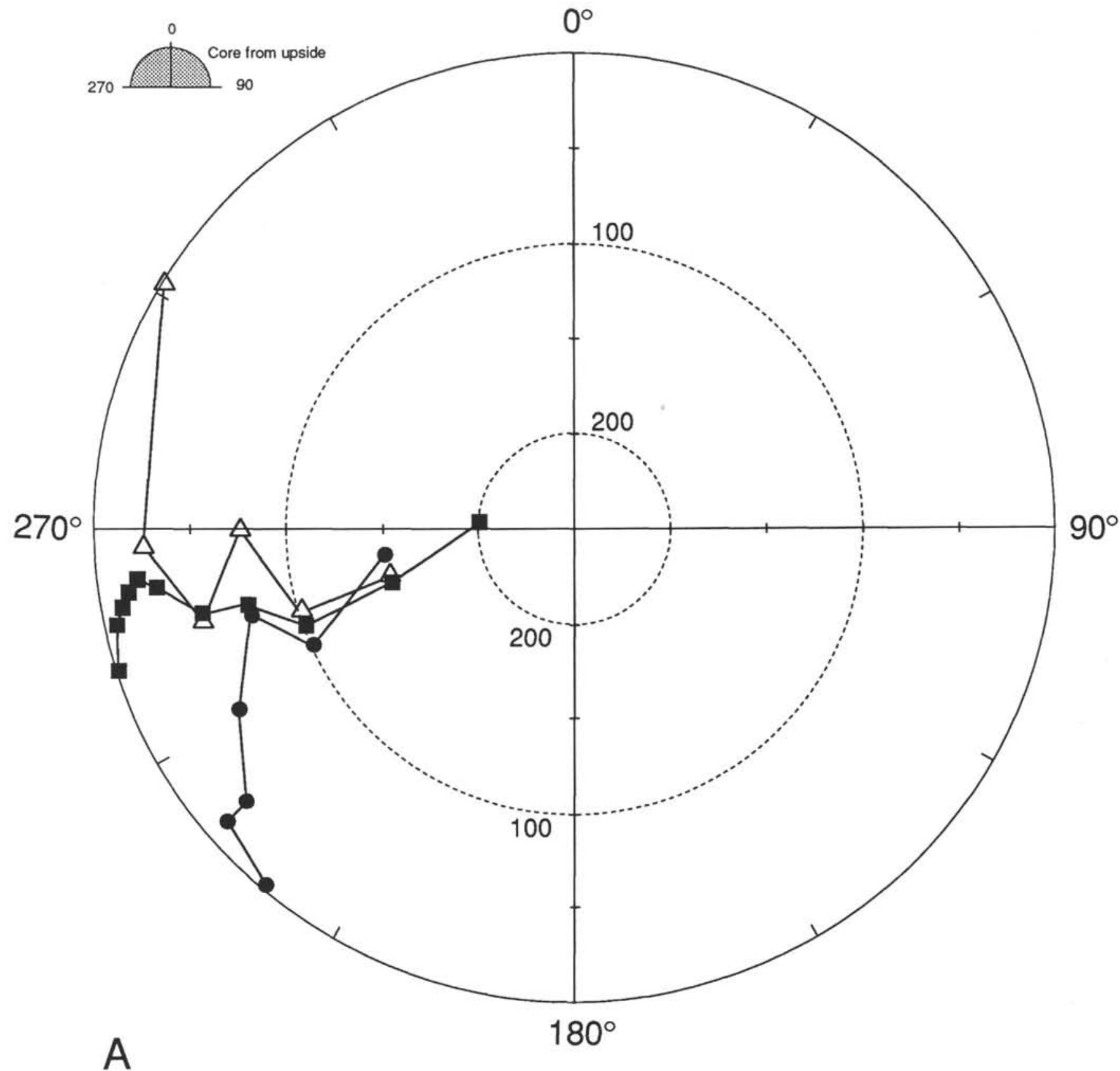

Figure 10. Plot of declinations on the equi-AF field of each sample taken from the same cutting split. A. Sample 121-758A-55R-2, 122-133 cm. B. Sample 121-758A-64R-1, 1-6, 94-96 cm. C. Sample 121-758A-69R-5, 36-47 cm. 


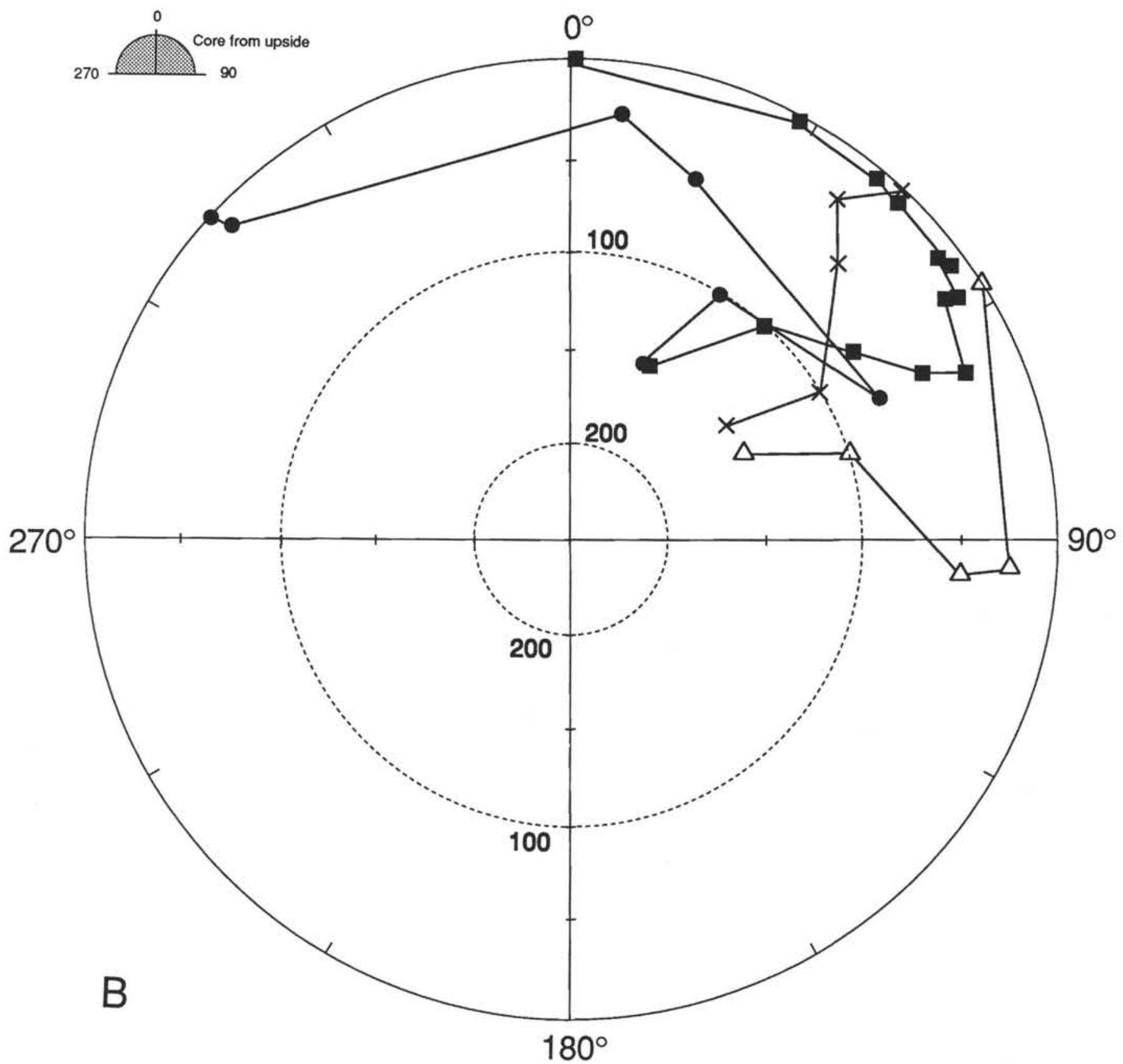

Figure 10 (continued). 
K. TAMAKI, K. YAMAMOTO, T. FURUTA, H. YAMAMOTO

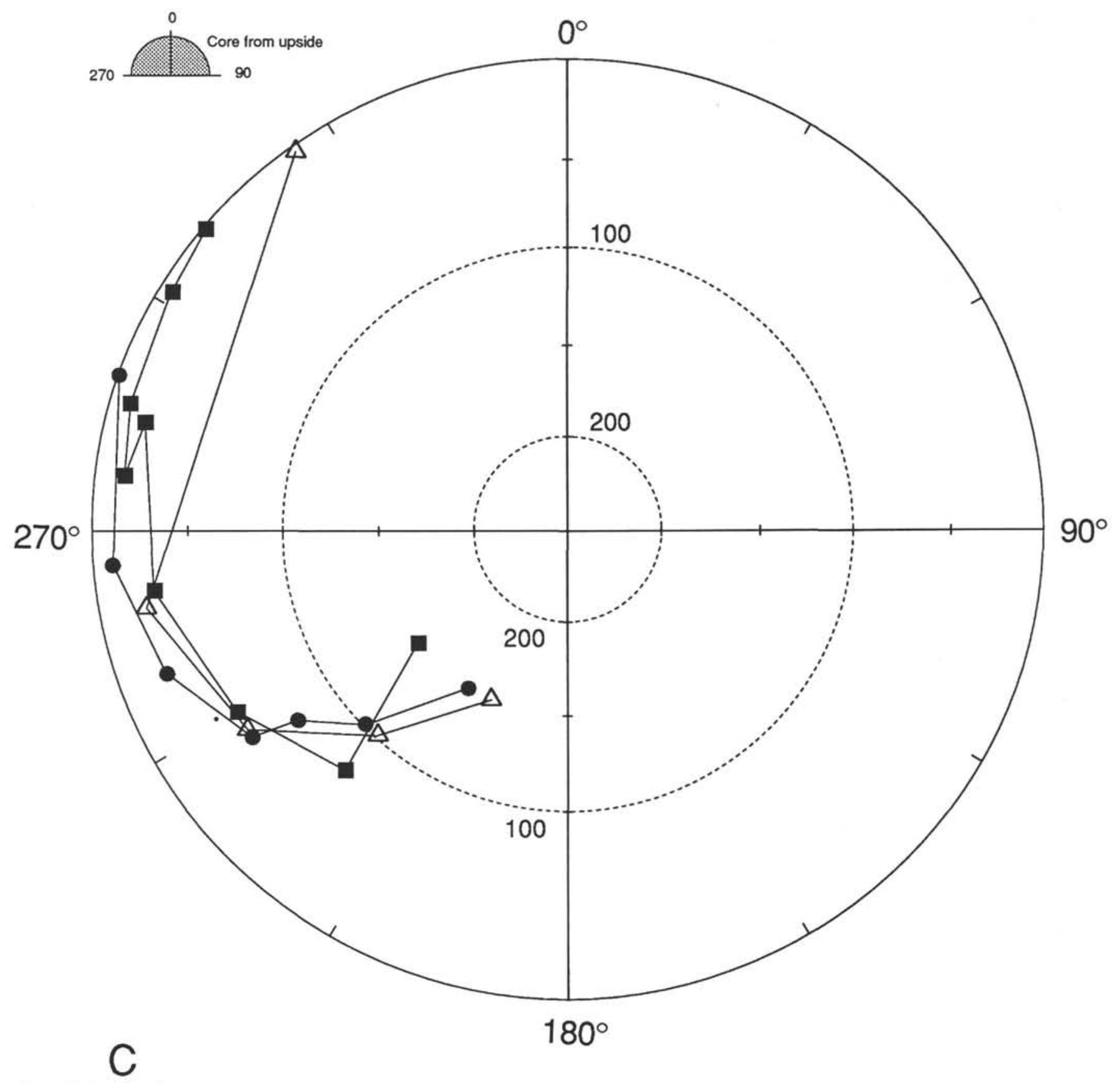

Figure 10 (continued). 
Table 2. Summary of measurements of previously applied stresses and correction for pore pressure effect.

\begin{tabular}{|c|c|c|c|c|c|c|c|}
\hline \multirow[b]{2}{*}{ Sample } & \multirow{2}{*}{$\underset{(\mathrm{MPa})}{\text { Vertical stress }}$} & \multicolumn{2}{|l|}{ reviously applied stress } & \multirow{2}{*}{$\begin{array}{l}\text { Correction for pore } \\
\text { pressure effect } \\
(\mathrm{MPa})\end{array}$} & \multicolumn{3}{|c|}{$\begin{array}{l}\text { Previously applied stress corrected for } \\
\text { pore pressure effect }\end{array}$} \\
\hline & & $\begin{array}{l}\text { Maximum horizontal } \\
\text { stress } \\
(\mathrm{MPa})\end{array}$ & $\begin{array}{c}\text { Minimum } \\
\text { horizontal stress } \\
(\mathrm{MPa})\end{array}$ & & $\begin{array}{l}\text { Vertical stress } \\
\text { (MPa) }\end{array}$ & $\begin{array}{c}\text { Maximum } \\
\text { horizontal stress } \\
(\mathrm{MPa})\end{array}$ & $\begin{array}{c}\text { Minimum } \\
\text { horizontal stress } \\
(\mathrm{MPa})\end{array}$ \\
\hline $121-758 \mathrm{~A}-55 \mathrm{R}-2,122-133 \mathrm{~cm}$ & $34.5 \pm 0.6$ & $33.3 \pm 0.6$ & $23.5 \pm 0.6$ & 3.3 & 37.8 & 36.6 & 26.8 \\
\hline $121-758 \mathrm{~A}-64 \mathrm{R}-1,1-6,94-96 \mathrm{~cm}$ & 35.5 & $35.0 \pm 1.0$ & $23.5 \pm 1.0$ & 5.1 & 40.6 & 40.1 & 28.6 \\
\hline $121-758 \mathrm{~A}-69 \mathrm{R}-5,36-47 \mathrm{~cm}$ & $37.6 \pm 0.6$ & $37.0 \pm 0.9$ & $26.8 \pm 0.9$ & 3.6 & 41.2 & 40.6 & 30.4 \\
\hline \multirow[b]{2}{*}{ Sample } & \multicolumn{3}{|c|}{$\begin{array}{l}\text { Estimated previously applied stress } \\
\text { corrected for pore pressure effect }\end{array}$} & \multirow{2}{*}{$\begin{array}{l}\text { Apparent direction } \\
\text { of maximum } \\
\text { horizontal stress } \\
\text { (degrees) }\end{array}$} & \multicolumn{2}{|c|}{ Geomagnetic NRM } & \multirow{2}{*}{$\begin{array}{c}\text { Estimated } \\
\text { orientation of maximum } \\
\text { horizontal stress } \\
\text { (degrees) }\end{array}$} \\
\hline & $\begin{array}{l}\text { correct } \\
\text { Vertical stress } \\
(\mathrm{MPa})\end{array}$ & $\begin{array}{c}\text { Maximum } \\
\text { horizontal stress } \\
(\mathrm{MPa})\end{array}$ & $\begin{array}{l}\text { Minimum } \\
\text { horizontal stress } \\
\text { (MPa) }\end{array}$ & & $\begin{array}{l}\text { Incli- } \\
\text { nation } \\
\text { (degrees) }\end{array}$ & $\begin{array}{cr}\begin{array}{c}\text { Decli- } \\
\text { nation } \\
\text { (degrees) }\end{array} & \text { orientat } \\
& \text { hor }\end{array}$ & \\
\hline $121-758 \mathrm{~A}-55 \mathrm{R}-2,122-133 \mathrm{~cm}$ & 37.8 & 36.6 & 26.8 & $F-68.6 \pm 2 E$ & -64 & 255 & N53W \\
\hline $121-758 \mathrm{~A}-64 \mathrm{R}-1,1-6,94-96 \mathrm{~cm}$ & 40.6 & 40.1 & 28.6 & $\mathrm{~F}-33.2 \pm 3 \mathrm{E}$ & -57 & 63 & N6W \\
\hline $121-758 \mathrm{~A}-69 \mathrm{R}-5,36-47 \mathrm{~cm}$ & 41.2 & 40.6 & 30.4 & $\mathrm{~F}-62.2 \pm 3 \mathrm{E}$ & -49 & 245 & N37W \\
\hline
\end{tabular}

Note: Apparent direction of the maximum horizontal stress is measured with a reference of the split surface as zero and clockwise increase of degree value. The reference of declination of NRM is shown in Figure 10. The reference of azimuth for the estimated orientation of the maximum horizontal stress is the geomagnetic north obtained from the stable magneti zation of each sample. 
121-758A-55R:Horizontal



A
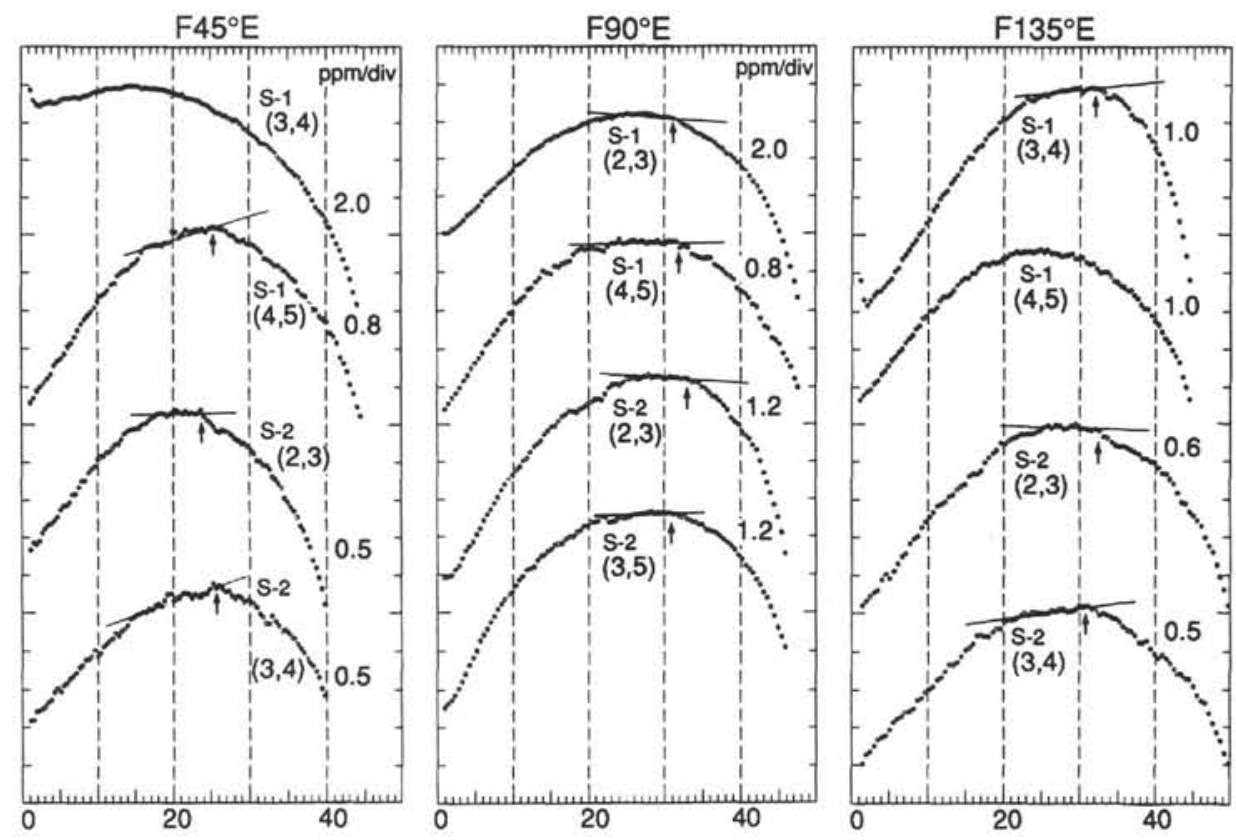

Axial stress (MPa)
121-758A-64R:Horizontal

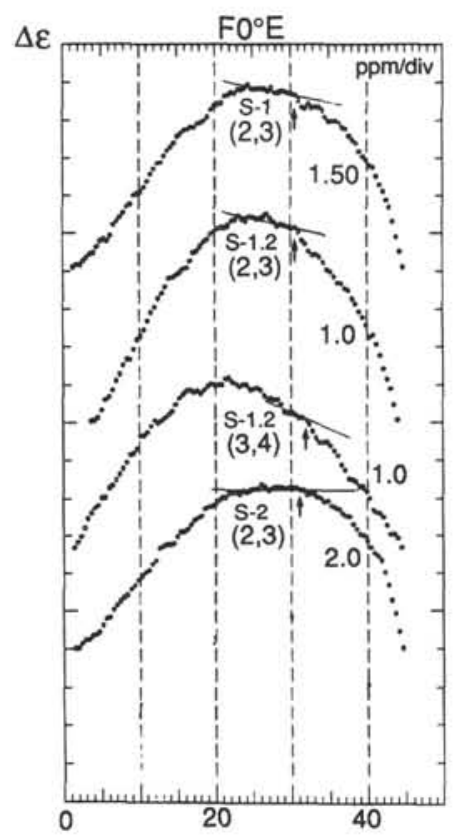

B
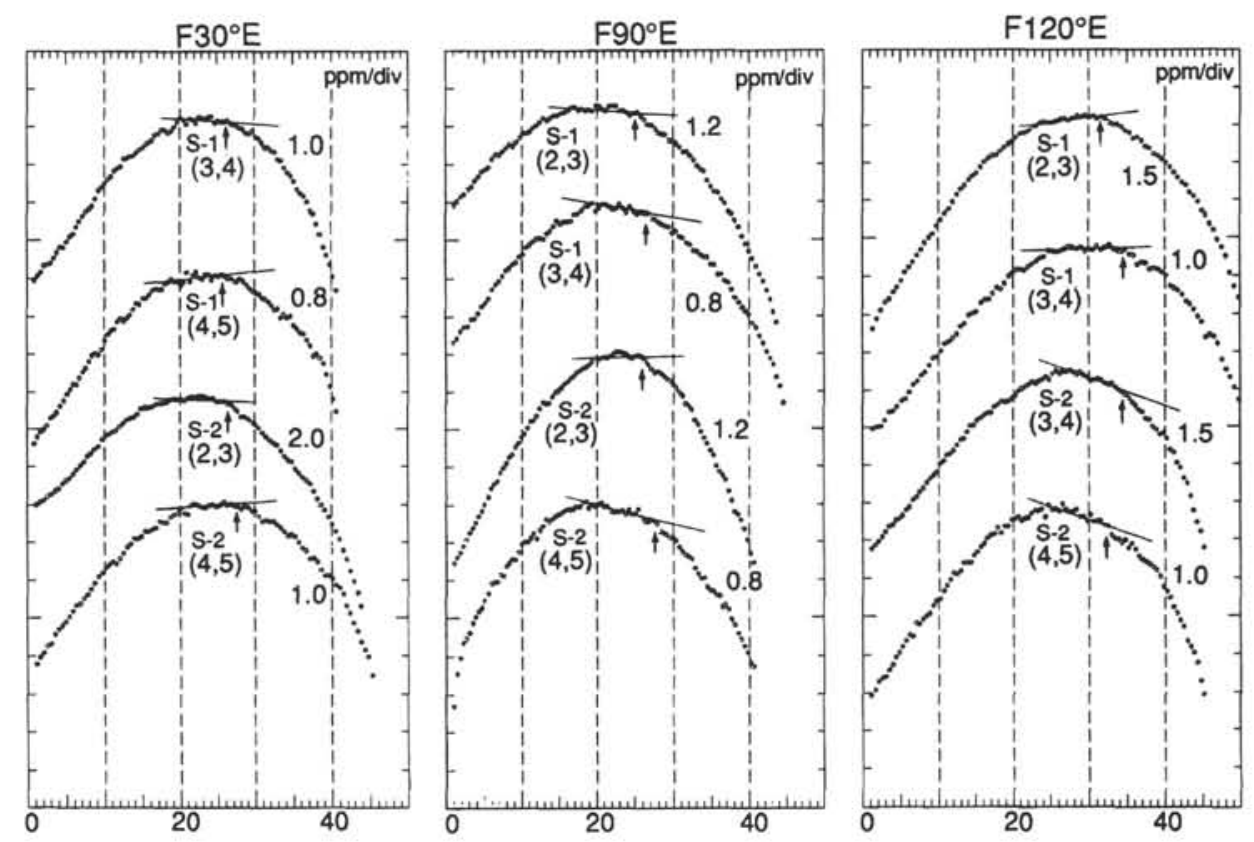

Axial stress (MPa)

Figure 11. Examples of the strain difference functions measured on the horizontal samples of Samples 121-758A-55R-2, 122-133 cm (A), 121-758A64R-1, 1-6, 94-96 cm (B), and 121-758A-69R-5, 36-47 cm (C). The functions for the same azimuth are shown in the same column. The azimuth is indicated at the top of each column. The symbols are the same as those in Figure 9. 
121-758A-69R:Horizontal

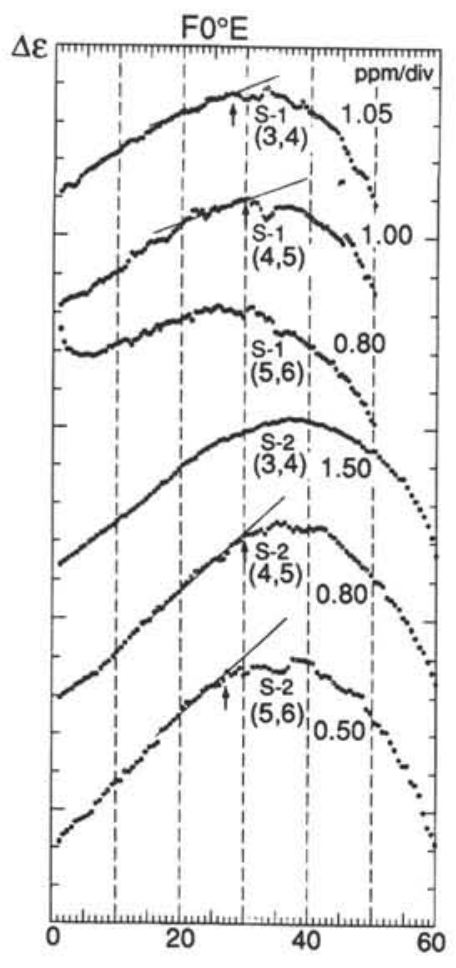

C
$\mathrm{F} 45^{\circ} \mathrm{E}$

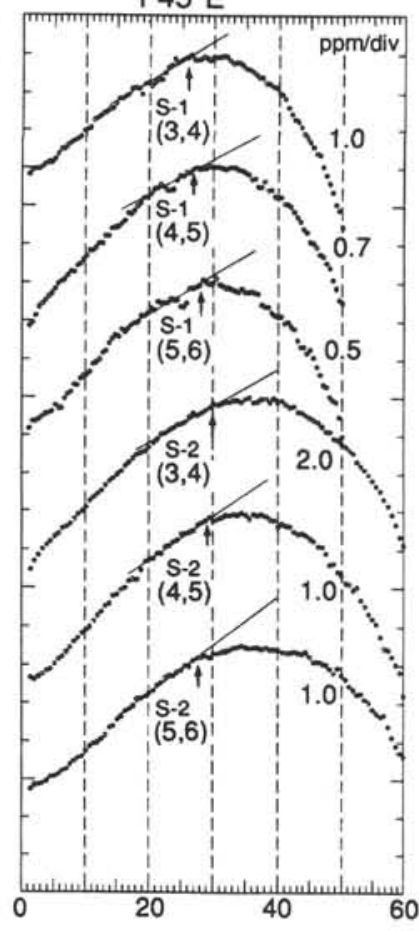

$\mathrm{F} 90^{\circ} \mathrm{E}$



Axial stress (MPa)

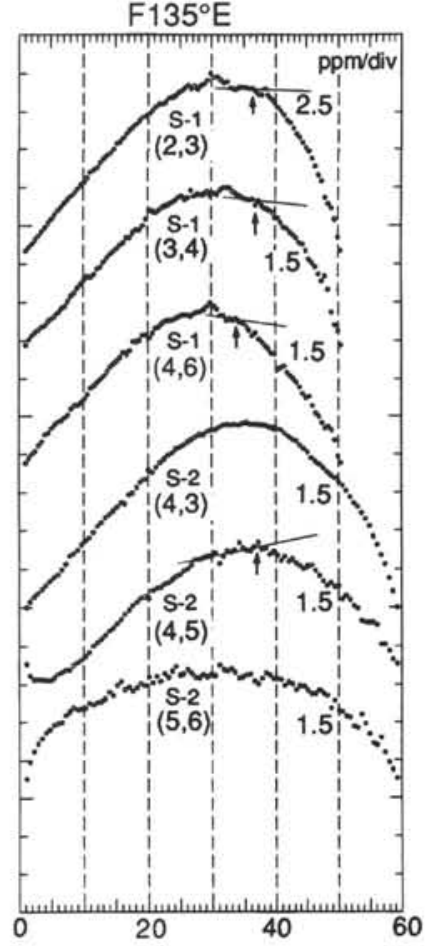

Figure 11 (continued). 
121-758A-55R

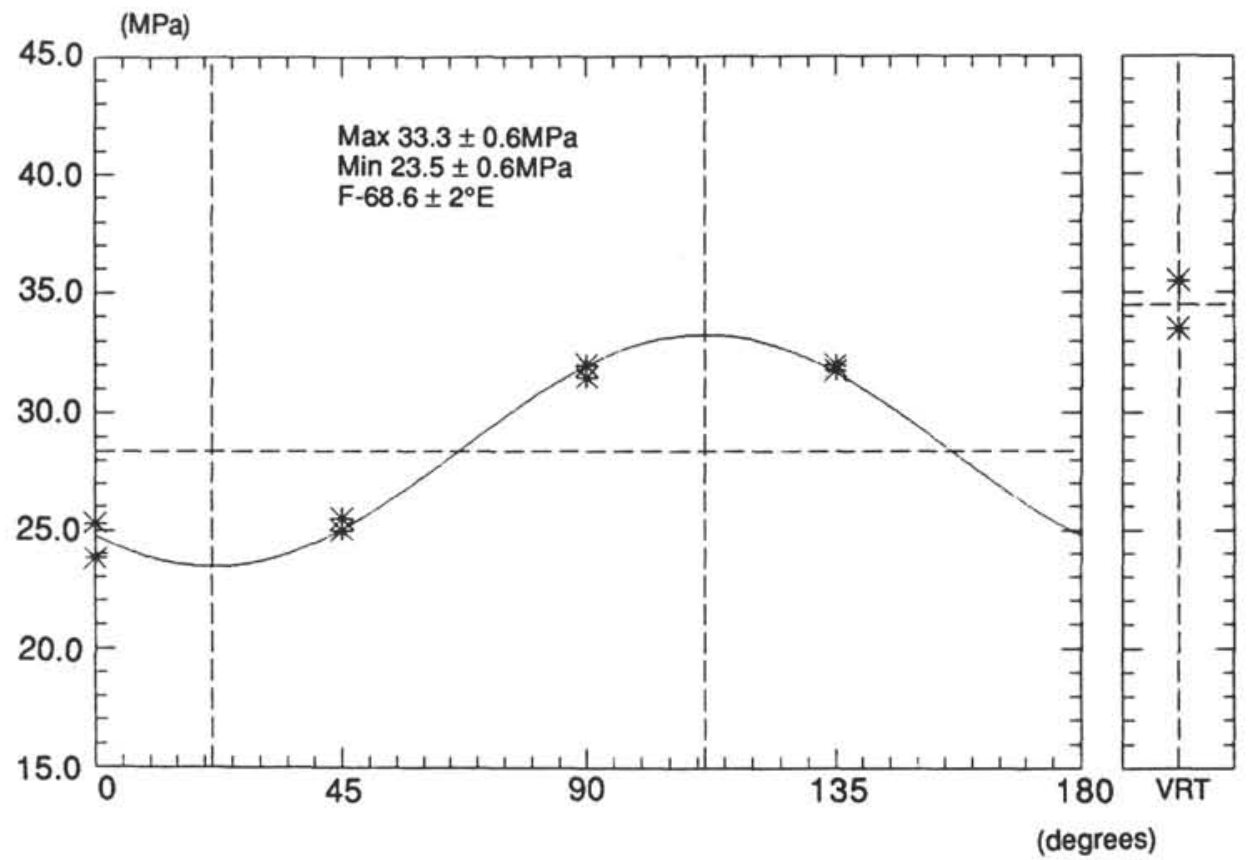

A

121-758A-64R

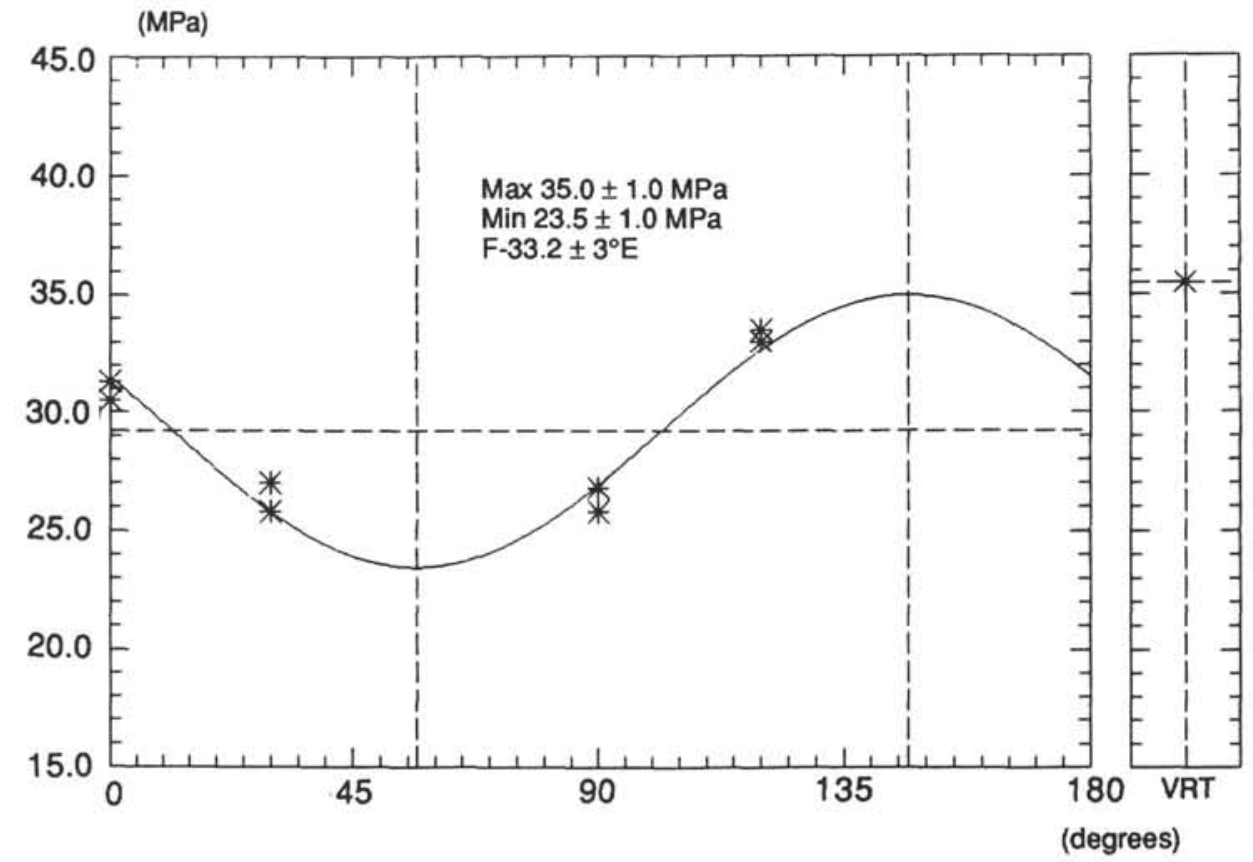

B

Figure 12. Azimuthal distribution of the previously applied peak stresses. The azimuth reference $(\mathrm{F})$ is specified for each cubic sample. The line shows the sinusoidal function fitted to the data by the least-squares method. The peak stress values for the vertical direction are plotted in the frame indicated by VRT. A. Sample 121-758A-55R-2, $122-133 \mathrm{~cm}$. B. Sample 121-758A-64R-1, 1-6, 94-96 cm. C. Sample 121-758A-69R-5, 36-47 cm. 
121-758A-69R

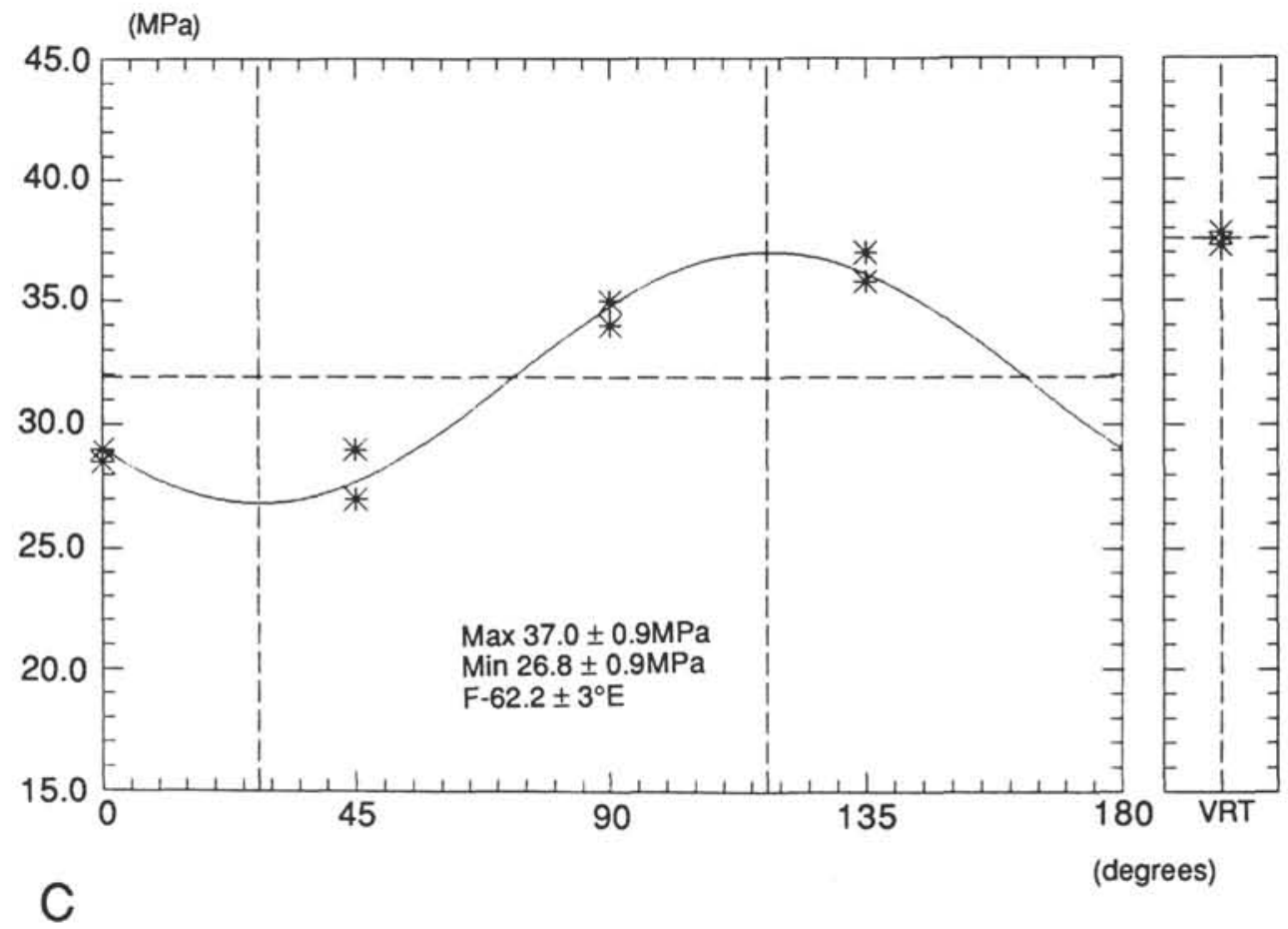

Figure 12 (continued). 